\title{
Engineering Biocoatings to Prolong Drug Release
}

\section{from Supraparticles}

Yutian Ma, ${ }^{\dagger}$, Christina Cortez-Jugo, ${ }^{\dagger}$ Jianhua Li, ${ }^{\dagger}$ Zhixing Lin,,$^{\dagger}$ Rachael T. Richardson,,$" \#$

Yiyuan Han,,$^{\dagger}$ Jiajing Zhou, ${ }^{\dagger}$ Mattias Björnmalm, ${ }^{\dagger}, \square$ Orlagh M. Feeney, ${ }^{\perp}$ Qi-Zhi Zhong, ${ }^{\dagger}$

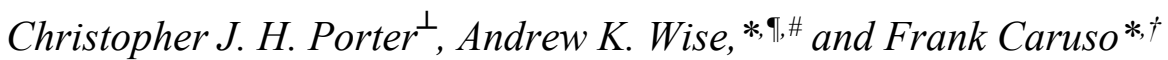

${ }^{\dagger}$ ARC Centre of Excellence in Convergent Bio-Nano Science and Technology, and the Department of Chemical Engineering, The University of Melbourne, Parkville, Victoria 3010, Australia.

"Bionics Institute, East Melbourne, Victoria 3002, Australia.

\#Department of Medical Bionics and Department of Otolaryngology, The University of Melbourne, Parkville, Victoria 3010, Australia.

${ }^{\square}$ Department of Materials, Department of Bioengineering, and the Institute of Biomedical Engineering, Imperial College London, London SW7 2AZ, UK.

${ }^{\perp}$ ARC Centre of Excellence in Convergent Bio-Nano Science and Technology, and Drug Delivery Disposition and Dynamics, Monash Institute of Pharmaceutical Sciences, Monash University, Parkville, Victoria 3052, Australia. 


\section{ABSTRACT}

Supraparticles (SPs) assembled from smaller colloidal nanoparticles can serve as depots of therapeutic compounds and are of interest for long-term, sustained drug release in biomedical applications. However, a key challenge to achieving temporal control of drug release from SPs is the occurrence of an initial rapid release of the loaded drug (i.e., "burst" release) that limits sustained release and potentially causes burst release-associated drug toxicity. Herein, a biocoating strategy is presented for silica-SPs (Si-SPs) to reduce the extent of burst release of the loaded model protein lysozyme. Specifically, the Si-SPs were coated with a fibrin film, formed by enzymatic conversion of fibrinogen into fibrin. The fibrin-coated Si-SPs, ${ }^{\mathrm{F}} \mathrm{Si}$-SPs, which could be loaded with $7.9 \pm 0.9 \mu \mathrm{g}$ of lysozyme per SP, released $>60 \%$ of cargo protein over a considerably longer period of time of $>20$ days when compared with the uncoated SiSPs that released the same amount of cargo protein, however, within the first 3 days. Neurotrophins that support the survival and differentiation of neurons could also be loaded at $\sim 7.3 \mu \mathrm{g}$ per SP, with fibrin coating also delaying neurotrophin release (only $10 \%$ of cargo released over 21 days compared with $60 \%$ from Si-SPs). In addition, the effects of incorporating a hydrogel-based system for surgical delivery and the opportunity to control drug release kinetics were investigated - an alginate-based hydrogel scaffold was used to encapsulate the ${ }^{\mathrm{F}} \mathrm{Si}-\mathrm{SPs}$. The introduction of the hydrogel further extended the initial release of the encapsulated lysozyme to $\sim 40$ days (for the same amount of cargo released). The results demonstrate the increasing versatility of the SP drug delivery platform, combining large loading capacity, with sustained drug release that is tailorable using different modes of controlled delivery approaches.

KEYWORDS: alginate, controlled release, fibrin, neurotrophin, silica, supraparticle 


\section{INTRODUCTION}

Nanotechnology has been widely investigated in the field of drug delivery to treat a diverse range of diseases such as cancer, ${ }^{1,2}$ viral infections, ${ }^{3}$ and neurological diseases. ${ }^{4,5}$ In drug delivery, the application of nanoengineered particles, such as liposomes, ${ }^{6}$ polymer particles, ${ }^{7}$ and mesoporous silica particles, ${ }^{8}$ can improve drug stability, prevent drug degradation and achieve controlled and sustained release of therapeutics. ${ }^{9}$ Sustained release drug delivery systems are of interest, particularly for applications where drug release is required over weeks or months, thereby reducing the frequency and amount of drug administration while eliciting the same (or improved) therapeutic effect. However, early and uncontrolled release of drug, or "burst release", is a major challenge in developing sustained release drug delivery systems. ${ }^{10}$ Burst release results in higher initial local drug concentrations, which, dependent on payload, can cause off-target toxicity. A second issue with burst release is the reduction in the effective lifetime of the drug delivery system; this is particularly relevant for nanocarriers where burst release could deplete a significant proportion of encapsulated drug due to short diffusional distances from the core to the surface of a nanoparticle. ${ }^{11}$ Various approaches have been investigated to minimize the extent of burst release from nanocarriers, including modifying the structure or surface of nanocarriers, ${ }^{12-16}$ conjugating drug and nanocarriers via covalent bonds, ${ }^{17}$ and coating the surface of nanocarriers. ${ }^{18,19}$

Recently, we reported the electrospray assembly of $\sim 550 \mu \mathrm{m}$ silica SPs (Si-SPs) composed of thousands of smaller porous silica particles. The Si-SPs could encapsulate up to $7 \mu \mathrm{g}$ of a model drug per SP and exhibited sustained, long-term drug release ( $>4$ months). ${ }^{20}$ One of our main interests in Si-SPs is for the inner ear delivery of neurotrophins for the treatment of hearing loss. Neurotrophins, including brain-derived neurotrophic factor (BDNF) and neurotrophin-3 (NT-3), are naturally occurring proteins expressed by certain types of cells within the inner ear including auditory neurons, hair cells, and supporting cells. ${ }^{21,22}$ 
Neurotrophins are important for supporting the differentiation and survival of auditory neurons, and hence are highly relevant drug candidates for encapsulation in Si-SPs for treating hearing loss. ${ }^{23,24}$ BDNF has been loaded in Si-SPs — which can be prepared using evaporation-induced self-assembly, ${ }^{25-27}$ mold-templating approaches, ${ }^{28,29}$ and gel-mediated electrospray assembly ${ }^{20}$-achieving protein loadings $\left(>100,000 \mathrm{ng} \mathrm{mg}^{-1}\right)^{20}$ that are several orders of magnitude higher than those achieved by comparable colloidal nanoparticle systems $(\sim 20 \mathrm{ng}$ $\left.\mathrm{mg}^{-1}\right) .{ }^{30}$ Importantly, BDNF-loaded Si-SPs have shown improved nerve survival when delivered in the inner ear of guinea pigs. ${ }^{27,31}$ For inner ear drug delivery, it is important to control the release kinetics of neurotrophins in the inner ear, as high local concentrations (e.g., due to burst release) may cause side effects such as seizures ${ }^{32}$ and epilepsy. ${ }^{33}$ Hence, reducing burst release to achieve sustained, continuous release over long periods (months) is critical for future clinical translation of the supraparticle technology.

Herein, we hypothesize that drug release from SPs can be slowed down using engineered coatings. A major consideration is the use of a material/coating that is biologically compatible to enable future clinical use. Thus, a bio-inspired strategy, using a biocoating and/or a composite hydrogel, is presented to reduce the extent of burst release of proteins pre-loaded in Si-SPs (Scheme 1). Specifically, our coating strategy is based on fibrin, an endogenous protein that is vital for blood clotting and hemostasis. Fibrin is a key component of the typical physiological response for the prevention of bleeding/hemorrhaging or blood clot formation: insoluble fibrin is enzymatically formed from fibrinogen, a glycoprotein present in blood plasma, which in the presence of thrombin becomes fibrin. ${ }^{34-36}$ We hypothesize that this bioinspired coating strategy (which mimics aspects of the blood clotting formation) would result in a compact fibrin coating with low permeability, thus delaying drug release from Si-SPs. This is similar to what is observed for coated surgical sutures. ${ }^{37}$ Our results showed a substantial delay in initial release: in the presence of uncoated Si-SPs, $>60 \%$ of drug release occurred in 
the first 3 days, whereas in the presence of the fibrin-coated Si-SPs ( ${ }^{\mathrm{F}} \mathrm{Si}-\mathrm{SPs}$ ) drug release extended to over $>20$ days (a $>6$-fold increase). Furthermore, cytotoxicity studies in the U87MG human brain glioblastoma cell line showed no adverse effects, and degradation studies provided further evidence for the biodegradability of the fibrin coating.

To facilitate future clinical use and surgical handling of the present SP drug delivery system, a hydrogel scaffold that gels upon application of external stimuli was developed by incorporating ${ }^{\mathrm{F}} \mathrm{Si}-\mathrm{SPs}$ within an injectable, biocompatible and biodegradable alginate-CaCO 3 particle (alg- $\left.\mathrm{CaCO}_{3}\right)$ hydrogel system. We previously reported approaches using poloxamerbased hydrogels that accelerated the release rate of drugs encapsulated in Si-SPs (thus exacerbating the burst release) ${ }^{20}$ In contrast, the alg- $\mathrm{CaCO}_{3}$ system presented herein reduced the initial drug release rate. Taken together, our results demonstrate that the incorporation of ${ }^{\mathrm{F}} \mathrm{Si}-\mathrm{SPs}$ into an alg- $\mathrm{CaCO}_{3}$ hydrogel matrix is a promising and potentially translatable platform for sustained and controlled protein delivery with substantially reduced burst release compared to conventional SP drug delivery systems. ${ }^{27,28}$ This approach has potential application in the treatment of middle ear or inner ear diseases with neurotrophins or other biomedical applications requiring sustained release.

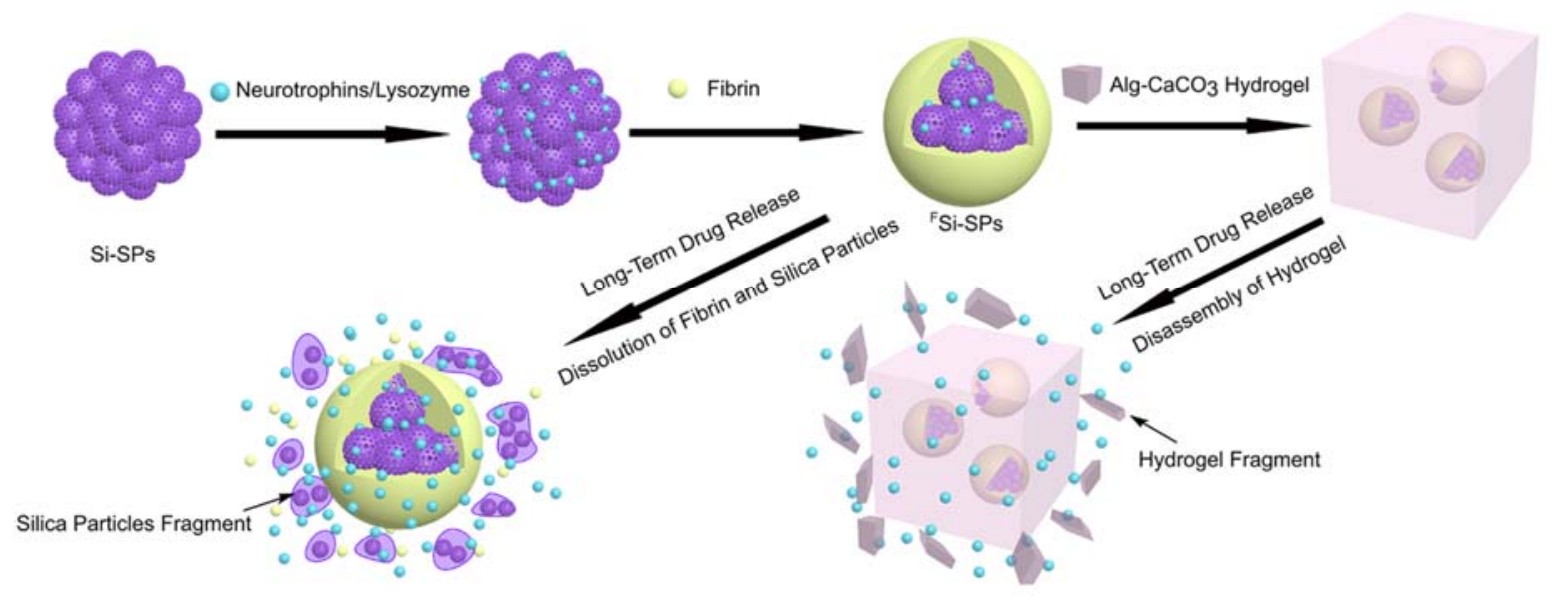

Scheme 1. Schematic illustration of the SP drug delivery systems developed in the present study. Si-SPs are pre-loaded with protein therapeutics (neurotrophins or the model protein 
lysozyme) before coating with fibrin to generate ${ }^{\mathrm{F}} \mathrm{Si}$-SPs. The coated SPs, ${ }^{\mathrm{F}} \mathrm{Si}$-SPs, are subsequently embedded in an alg- $\mathrm{CaCO}_{3}$ hydrogel system. ${ }^{\mathrm{F}} \mathrm{Si}$-SPs exhibit reduced initial burst release (compared to uncoated Si-SPs). Hydrogel encapsulation further reduces initial burst release. Long-term, sustained release of the preloaded protein is obtained through degradation of fibrin, silica SPs and hydrogel.

\section{EXPERIMENTAL SECTION}

Materials. Cetyltrimethylammonium bromide (CTAB), tetraethyl orthosilicate (TEOS), ammonium hydroxide solution (28-30\%), poly(acrylic acid) (PAA, $M_{\mathrm{w}} \sim 250 \mathrm{kDa}, 35 \mathrm{wt} \%$ aqueous solution), fluorescein isothiocyanate (FITC), lysozyme protein from chicken egg white, alginic acid sodium salt from brown algae (alginate), calcium chloride $\left(\mathrm{CaCl}_{2}\right)$, phosphate-buffered saline (PBS, pH 7.4), fibrinogen from human plasma, phenazine methosulfate (PMS), Dulbecco's phosphate-buffered saline (DPBS), sodium hydroxide $(\mathrm{NaOH})$, poly(sodium 4-styrenesulfonate) (PSS), sodium carbonate $\left(\mathrm{Na}_{2} \mathrm{CO}_{3}\right)$, D-glucono- $\delta$ lactone (GDL), and silicon standard for the inductively coupled plasma experiments were purchased from Sigma-Aldrich (USA). Thrombin reagent was purchased from Siemens (Australia). Hydrochloric acid, sodium chloride $(\mathrm{NaCl})$, tris(hydroxymethyl)methylamine (Tris) and calcium nitrate tetrahydrate $\left(\mathrm{Ca}\left(\mathrm{NO}_{3}\right)_{2} \cdot 4 \mathrm{H}_{2} \mathrm{O}\right)$ were obtained from Chem-Supply (Australia). 2,3-Bis[2-methoxy-4-nitro-5-sulfophenyl]-2H-tetrazolium-5-carboxyanilide inner salt (XTT), the Micro BCA protein assay kit, and NT-3 enzyme-linked immunosorbent assay (ELISA) kits were purchased from Thermo Fisher Scientific (Australia). The U87MG human brain glioblastoma cell line was purchased from American Type Culture Collection (USA). Biowhittaker Dulbecco's Modified Eagle's Medium (DMEM) was obtained from Lonza (Australia). BDNF and NT-3 were purchased from PeproTech Asia (Israel), and human BDNF ELISA kits were obtained from Abcam (Australia). Ethanol was purchased from Chem-Supply (Australia). Ultrapure water (Milli-Q water) with a resistivity of greater than $18 \mathrm{M} \Omega \mathrm{cm}$ was 
used in all experiments and obtained from a three-stage Millipore Milli-Q Plus 185 purification system. All chemicals were used without further purification.

Synthesis of Primary Silica Particles. Primary silica particles $(\sim 1 \mu \mathrm{m}$ diameter $)$ were synthesized using a modified version of a previously published protocol. ${ }^{38}$ Briefly, $1.1 \mathrm{~g}$ of CTAB was dissolved in $50 \mathrm{~mL}$ of Milli-Q water followed by mixing with $4.3 \mathrm{~g}$ of PAA under vigorous stirring at room temperature (i.e., $\sim 22^{\circ} \mathrm{C}$ ). After $20 \mathrm{~min}$, a clear solution was obtained, to which $3.5 \mathrm{~mL}$ of ammonium hydroxide solution (28-30\%) was added with vigorous stirring for $20 \mathrm{~min}$, resulting in a milky suspension. TEOS $(4.46 \mathrm{~mL})$ was then added with vigorous stirring for $15 \mathrm{~min}$. Subsequently, the mixture was placed into a Teflon-sealed autoclave at 90 ${ }^{\circ} \mathrm{C}$ for $48 \mathrm{~h}$. The silica particles were removed from the Teflon-sealed autoclave and washed with Milli-Q water and ethanol twice, followed by drying at $80{ }^{\circ} \mathrm{C}$ overnight. Finally, the primary silica particles were placed in a chamber furnace (Jetlow, Australia) and calcined at $550{ }^{\circ} \mathrm{C}$ for $30 \mathrm{~h}$ to remove any organic materials.

Synthesis of Silica SPs. The silica SPs (Si-SPs) were assembled using an electrospray method as described previously. ${ }^{20}$ Briefly, $80 \mathrm{mg}$ of the primary silica particles was dispersed in $2 \mathrm{~mL}$ of aqueous alginate solution $\left(30 \mathrm{mg} \mathrm{mL}^{-1}\right.$ in Milli-Q water). After mixing, the suspension was ultra-sonicated using an ultrasonic processor with a microtip probe (Qsonica, CT, USA) at an output amplitude of $30 \%$ for $40 \mathrm{~s}$ and sonicated further in an ultrasonic cleaner (Branson, USA) for $1 \mathrm{~h}$ to disperse the primary silica particles evenly within the alginate solution. Subsequently, the solution was poured into a syringe, which was positioned in a syringe pump set at a constant flow rate of $8 \mathrm{~mL} \mathrm{~h}^{-1}$. An applied voltage of $13 \mathrm{kV}$ was used in the electrospray setup to drip the alginate/primary silica particle solution into a reservoir of $1 \%$ w/v of aqueous $\mathrm{CaCl}_{2}$. A $10 \mathrm{~cm}$ collector distance was set between the end of the nozzle and the surface of the $\mathrm{CaCl}_{2}$ solution. After $5 \mathrm{~min}$, the alginate/silica SPs $\left(\mathrm{Si}-\mathrm{SPs}^{\mathrm{alg}}\right)$ were collected directly from the $\mathrm{CaCl}_{2}$ bath using a strainer and washed extensively in Milli-Q water (four 
times). Finally, the alginate was removed from the Si-SPs ${ }^{\text {alg }}$ by calcination at $650{ }^{\circ} \mathrm{C}$ for $30 \mathrm{~h}$ to produce the Si-SPs. The density of the Si-SPs is $\sim 71.8 \mu \mathrm{g} \mathrm{cm}^{-3}$, calculated using the mass of individual Si-SPs divided by the volume of individual Si-SPs (mass and diameter of SPs are measured, and then density is approximated by assuming that the individual Si-SPs are perfect spheres).

Synthesis and In Vitro Fibrin Degradation of ${ }^{\mathrm{F}} \mathrm{Si}-\mathrm{SPs}$. The preparation of ${ }^{\mathrm{F}} \mathrm{Si}$-SPs is schematically illustrated in Scheme 1. Typically, ten Si-SPs were placed in a $1.7 \mathrm{~mL}$ Eppendorf tube and sterilized with $100 \mu \mathrm{L}$ of $80 \%(\mathrm{v} / \mathrm{v})$ ethanol at $\sim 22{ }^{\circ} \mathrm{C}$ for $4 \mathrm{~h}$. The SPs were then washed with Milli-Q water six times (after sterilization, Si-SPs were handled under aseptic conditions in a biosafety cabinet). Then, $50 \mu \mathrm{L}$ of $20 \mathrm{mg} \mathrm{mL}^{-1}$ fibrinogen dissolved in $50 \mathrm{mM}$ Tris-buffered saline (TBS; $50 \mathrm{mM}$ Tris, $150 \mathrm{mM} \mathrm{NaCl}$ with $\mathrm{pH}$ adjusted to 7.2) was added to the Si-SPs and incubated at $4{ }^{\circ} \mathrm{C}$ overnight $(\sim 16 \mathrm{~h})$. The supernatant was then aspirated and the Si-SPs were incubated with $50 \mu \mathrm{L}$ of $1.72 \mathrm{mg} \mathrm{mL}^{-1}$ thrombin in $50 \mathrm{mM}$ TBS, containing 40 $\mathrm{mM} \mathrm{CaCl}_{2}$ at $\sim 22^{\circ} \mathrm{C}$ for $1 \mathrm{~h}$. Finally, the supernatant was aspirated and the Si-SPs were washed with Milli-Q water three times.

The degradation of fibrin from ${ }^{\mathrm{F}} \mathrm{Si}$-SPs was assessed by incubation of ${ }^{\mathrm{F}} \mathrm{Si}$-SPs with $100 \mu \mathrm{L}$ of PBS (pH 7.4) at $37{ }^{\circ} \mathrm{C}$ (with ten ${ }^{\mathrm{F}} \mathrm{Si}$-SPs in each sample). At specific time intervals (up to 42 days), $95 \mu \mathrm{L}$ of supernatant was collected and stored at $-20^{\circ} \mathrm{C}$ for further analysis, and then replaced with $95 \mu \mathrm{L}$ of fresh PBS. The concentration of degraded fibrin in the supernatant was quantified using a Micro BCA protein assay kit based on the manufacturer's protocol. The degradation percentage of fibrin was calculated as follows:

$$
\text { Percentage of fibrin remaining }=\frac{m_{0}-m_{n}}{m_{0}} \times 100 \%
$$

where $m_{0}$ is the initial amount of fibrin on the SPs and $m_{n}$ is the amount of fibrin in the supernatant at time point $n$. 
Synthesis of $\mathrm{CaCO}_{3}$ Particles. $\mathrm{CaCO}_{3}$ particles were synthesized using a previously described protocol ${ }^{39}$ with modifications. First, $5 \mathrm{~g}$ of PSS $\left(M_{\mathrm{w}} 70 \mathrm{kDa}\right)$ was dissolved in 500 $\mathrm{mL}$ of Milli-Q water to form $10 \mathrm{mg} \mathrm{mL}^{-1}$ PSS solution. Then, a precursor solution consisting of $1 \mathrm{~mL}$ of $1 \mathrm{M} \mathrm{Na}_{2} \mathrm{CO}_{3}, 0.5 \mathrm{~mL}$ of $10 \mathrm{mg} \mathrm{mL}^{-1} \mathrm{PSS}$, and $3.5 \mathrm{~mL}$ of Milli-Q water was prepared. In a separate flask, $20 \mathrm{~mL}$ of $10 \mathrm{mg} \mathrm{mL}^{-1}$ PSS solution was added to $175 \mathrm{~mL}$ of Milli-Q water with vigorous stirring. After stirring for $1 \mathrm{~min}, 5 \mathrm{~mL}$ of $1 \mathrm{M} \mathrm{Ca}\left(\mathrm{NO}_{3}\right)_{2} \cdot 4 \mathrm{H}_{2} \mathrm{O}$ solution was added with vigorous stirring for $2 \mathrm{~min}$. The precursor solution $(5 \mathrm{~mL})$ was then added and the resulting mixture was stirred vigorously for $1 \mathrm{~min}$, after which the stirrer was turned off and the mixture allowed to stand for $3 \mathrm{~min}$, followed by another vigorous stirring for $1 \mathrm{~min}$. The as-synthesized $\mathrm{CaCO}_{3}$ particles were dried overnight in an oven at $80{ }^{\circ} \mathrm{C}$ and subsequently ground using a mortar and pestle. The fine $\mathrm{CaCO}_{3}$ powder was then calcined with air flow at $500{ }^{\circ} \mathrm{C}$ for $2 \mathrm{~h}$ to remove any organic materials.

Preparation and In Vitro Degradation of the $\mathrm{Alg}-\mathrm{CaCO}_{3} \mathrm{Hydrogel}$. To prepare the hydrogel, $1 \mathrm{~mL}$ of $20 \mathrm{mg} \mathrm{mL}^{-1}$ alginate solution in Milli-Q water was mixed with $15 \mu \mathrm{L}$ of 100 $\mathrm{mg} \mathrm{mL}{ }^{-1} \mathrm{CaCO}_{3}$ particles (particle diameter $\sim 1.8 \mu \mathrm{m}$, see Figure $\mathrm{S} 1$ ). Following this, $53.4 \mu \mathrm{L}$ of $100 \mathrm{mg} \mathrm{mL}^{-1} \mathrm{GDL}$ was added to achieve a $\mathrm{CaCO}_{3}$ particles-to-GDL molar ratio of 1:2, resulting in a neutral $\mathrm{pH}$ value of the formed hydrogel. The gelation time of the hydrogel can be tuned by adjusting the concentration of the alginate solution and/or the amount of $\mathrm{CaCO}_{3}$ particles. $^{40}$

To study the degradability of the alg- $\mathrm{CaCO}_{3}$ hydrogel, the mass (dry weight) of the hydrogel was monitored over time. PBS $(500 \mu \mathrm{L}, \mathrm{pH} 7.4)$ was added to the hydrogel $(500 \mu \mathrm{L}$ of $20 \mathrm{mg}$ $\mathrm{mL}^{-1}$ alg- $\mathrm{CaCO}_{3}$ hydrogel $)$ and incubated at $37^{\circ} \mathrm{C}$. At various time points $(0,3,7,14,21,28$ and 42 days), PBS was removed, and the remaining hydrogel samples were washed with MilliQ water (five times), and frozen and stored at $-20^{\circ} \mathrm{C}$ until analysis. For the longer time points, PBS was replaced with $500 \mu \mathrm{L}$ of fresh PBS and the sample was returned to the incubator set 
at $37{ }^{\circ} \mathrm{C}$ until the next time point. All remaining samples were lyophilized, and the dry weight of the hydrogel was measured. The weight loss percentage was calculated as follows:

$$
\text { Weight loss }(\%)=\frac{m_{0}-m_{n}}{m_{0}} \times 100 \%
$$

where $m_{0}$ is the initial weight of the hydrogel at time point 0 and $m_{\mathrm{n}}$ is the weight of hydrogel at time point $n$.

Characterization. Scanning electron microscopy (SEM) images of Si-SPs, ${ }^{\mathrm{F}} \mathrm{Si}$-SPs and $\mathrm{CaCO}_{3}$ particles were taken using a Philips XL30 field-emission scanning electron microscope (Philips, Netherlands) at an operating voltage of $5 \mathrm{kV}$. SEM samples of the SPs were prepared by depositing them onto conductive carbon tape followed by sputter coating to obtain a $20 \mathrm{~nm}$ gold coating on the samples. SEM-energy-dispersive X-ray spectroscopy (SEM-EDX) mapping of ${ }^{\mathrm{F}} \mathrm{Si}$-SPs was performed on a Philips XL30 field-emission scanning electron microscope (Philips, Netherlands). Prior to analysis, the alg- $\mathrm{CaCO}_{3}$ hydrogel was lyophilized overnight. The lyophilized sample was then placed directly onto conductive carbon tape followed by gold sputter coating for imaging. Fourier-transform infrared (FTIR) spectra of SiSPs and Fi-SPs were collected using a FTIR spectrophotometer (Bruker, Australia). The thickness and surface roughness of the fibrin coating were characterized by atomic force microscopy (AFM; JPK nanoWizard II BioAFM) in contact mode. Briefly, a glass microscope slide was cleaned using a plasma cleaner. Fibrinogen solution was added onto the glass slide, incubated overnight at $4{ }^{\circ} \mathrm{C}$, and washed with Milli-Q water. For the preparation of the fibrin coating, thrombin solution was added to the fibrinogen film and incubated for $1 \mathrm{~h}$ at room temperature $\left(22^{\circ} \mathrm{C}\right)$ followed by washing with Milli-Q water. To measure the thickness, a scalpel blade was used to scratch the dry fibrinogen or fibrin film and images were taken at several points on the edge of the scratch. Film thickness and surface roughness analyses were carried out using the JPKSPM data processing software. The thickness and surface roughness values obtained were averaged and reported as mean \pm standard deviation. 
In Vitro Release Studies. In vitro release studies were conducted using either the model drug FITC-lysozyme or neurotrophin (BDNF or NT-3). Following sterilization of the Si-SPs with $80 \% \mathrm{v} / \mathrm{v}$ ethanol and the synthesis of ${ }^{\mathrm{F}} \mathrm{Si}-\mathrm{SPs}$ (as described earlier), ten Si-SPs were incubated with $100 \mu \mathrm{L}$ of FITC-lysozyme solution ( $1 \mathrm{mg} \mathrm{mL}^{-1}$ in Milli-Q water) in a $1.7 \mathrm{~mL}$ Eppendorf tube and mixed for 3 days at room temperature $\left(22^{\circ} \mathrm{C}\right)$. After incubation, the supernatant was aspirated to remove unbound lysozyme and the particles were washed with $100 \mu \mathrm{L}$ of Milli-Q water three times. FITC-lysozyme loaded Si-SPs were coated with fibrin as described above. To study FITC-lysozyme release, $100 \mu \mathrm{L}$ of fresh PBS (as the elution buffer) was added to the loaded Si-SPs or ${ }^{\mathrm{F}} \mathrm{Si}-\mathrm{SPs}$. At defined time intervals (over 150 days), $95 \mu \mathrm{L}$ of the supernatant was collected (and stored at $-20{ }^{\circ} \mathrm{C}$ until analysis) and replaced with $95 \mu \mathrm{L}$ of fresh PBS. The fluorescence of the collected samples was measured using an Infinite M200 microplate reader (Tecan, Switzerland), and the concentration of FITC-lysozyme in the supernatant was calculated using a FITC-lysozyme standard curve (Figure S2). FITC-lysozyme release from ${ }^{\mathrm{F}} \mathrm{Si}$-SPs was also assessed as a function of fibrinogen concentration $\left(2,20\right.$, and $\left.40 \mathrm{mg} \mathrm{mL}^{-1}\right)$ at a given concentration $\left(1.72 \mathrm{mg} \mathrm{mL}^{-1}\right)$ of thrombin (the resulting samples are referred to as ${ }^{2 \mathrm{~F} 1.72} \mathrm{Si}-\mathrm{SPs},{ }^{20 \mathrm{~F} 1.72} \mathrm{Si}-\mathrm{SPs}$, and ${ }^{40 \mathrm{~F} 1.72} \mathrm{Si}-\mathrm{SPs}$, respectively) and as a function of thrombin concentration $\left(0.1,0.5,1.72\right.$, and $\left.5 \mathrm{mg} \mathrm{mL}^{-1}\right)$ at a given concentration $\left(20 \mathrm{mg} \mathrm{mL}^{-1}\right)$ of

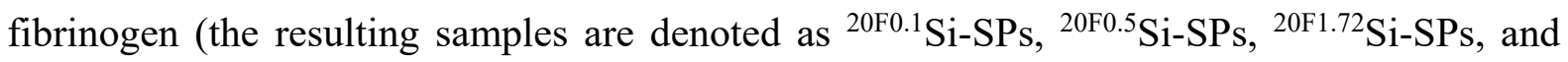
${ }^{20 \mathrm{~F} 5} \mathrm{Si}-\mathrm{SPs}$, respectively). A description, including nomenclature, of the particles prepared in the present study is given in Table S1.

For neurotrophin (BDNF or NT-3) loading, four sterilized Si-SPs were incubated with $30 \mu \mathrm{L}$ of BDNF or NT-3 solution (1.0 mg mL $\mathrm{mL}^{-1}$ in Milli-Q water). After incubation for 3 days, the supernatant was removed, and the SPs were placed in separate $1.7 \mathrm{~mL}$ microcentrifuge tubes (one SP per tube). For loading FSi-SPs, the neurotrophin was loaded into Si-SPs followed by fibrin coating that is mentioned above. Then, $100 \mu \mathrm{L}$ of PBS ( $\mathrm{pH} 7.4$ ) was added to each tube 
and incubated at $37^{\circ} \mathrm{C}$. At defined time points ( $\sim 28$ days), $95 \mu \mathrm{L}$ of the supernatant was collected (and stored at $-20{ }^{\circ} \mathrm{C}$ until analysis) and replaced with $95 \mu \mathrm{L}$ of fresh PBS. This sampling method was repeated at each time point over the course of the release studies. The amount of BDNF or NT-3 released from Si-SPs or ${ }^{\mathrm{F}} \mathrm{Si}$-SPs was determined using a BDNF- or NT-3-specific ELISA using a standard curve of BDNF or NT-3 as per the manufacturer's protocol (Figure S3).

The release of FITC-lysozyme from ${ }^{\mathrm{F}} \mathrm{Si}-\mathrm{SPs}$ embedded in the hydrogel was determined as follows. Alginate solution was mixed with $\mathrm{CaCO}_{3}$ particles as described above. Prior to gelation, $10{ }^{\mathrm{F}} \mathrm{Si}-\mathrm{SPs}$ (pre-loaded with FITC-lysozyme for 3 days) were added to the alg- $\mathrm{CaCO}_{3}$ mixture. To induce gelation, GDL was added at the same concentration and volume as described above. After $\sim 2 \mathrm{~min}$, the hydrogel formed. To study the release in PBS, $100 \mu \mathrm{L}$ of PBS (pH 7.4) was added and the sample was incubated at $37^{\circ} \mathrm{C}$. At defined time points (over 110 days), $95 \mu \mathrm{L}$ of supernatant was collected (and stored at $-20^{\circ} \mathrm{C}$ until analysis) and replaced with fresh PBS. The fluorescence of the collected samples was measured with an Infinite M200 microplate and the corresponding FITC-lysozyme concentration was determined using a standard curve (Figure S4).

Note that for all comparisons presented in individual figures, release experiments were performed simultaneously and fluorescence measurement of the collected samples was performed on the same day using the same standard curve.

In Vitro Si-SPs and FSi-SPs Degradation Studies. Si-SPs were first sterilized with $100 \mu \mathrm{L}$ of ethanol $(80 \% \mathrm{v} / \mathrm{v})$ at $\sim 22{ }^{\circ} \mathrm{C}$ for $4 \mathrm{~h}$, and then washed with Milli-Q water four times (following sterilization, SP handling was performed in a biosafety cabinet using aseptic technique). Subsequently, ${ }^{\mathrm{F}} \mathrm{Si}$-SPs were prepared as described above. SP degradation was studied by immersing Si-SPs or ${ }^{\mathrm{F}} \mathrm{Si}-\mathrm{SPs}$ (20 SPs per sample tested) in $1 \mathrm{~mL}$ of $10 \mathrm{mM}$ PBS $(\mathrm{pH} 7.4)$ at $37^{\circ} \mathrm{C}$. At defined time points (over 70 days), $1 \mathrm{~mL}$ of the supernatant was collected 
and replaced with $1 \mathrm{~mL}$ fresh PBS. The presence of silica degradation product in the supernatant was measured using inductively coupled plasma-optical emission spectroscopy (ICP-OES). Sodium hydroxide $(8 \mathrm{M}, 500 \mu \mathrm{L})$ was added to $500 \mu \mathrm{L}$ of each collected supernatant to dissolve any silica fragments. The samples were incubated at $95^{\circ} \mathrm{C}$ for $30 \mathrm{~min}$, followed by $30 \mathrm{~min}$ of sonication. The samples were then incubated overnight at $37^{\circ} \mathrm{C}$. The dissolved sample ( $1 \mathrm{~mL})$ was mixed with $4 \mathrm{~mL}$ of Milli-Q water, resulting in a 10-fold sample dilution from the originally collected supernatant. The amount of silicon in each sample (corresponding to the released silicon from the SPs) was measured by ICP-OES using a silicon standard curve (Figure S5). In addition to these measurements, the morphology of Si-SPs and ${ }^{\mathrm{F}} \mathrm{Si-SPs}$ after long-term incubation in PBS was observed by SEM.

Cytotoxicity. First, Si-SPs were sterilized with $100 \mu \mathrm{L}$ of ethanol $(80 \% \mathrm{v} / \mathrm{v})$ at $\sim 22{ }^{\circ} \mathrm{C}$ for 4 h, followed by washing sequentially with Milli-Q water (three times) and cell culture medium (three times). After sterilization, Si-SPs were handled in a biosafety cabinet using aseptic technique. To determine the cytotoxicity of the degradation products of the SPs, $1 \mathrm{~mL}$ of cell culture media (DMEM supplemented with $10 \%$ fetal bovine serum, 100 units $\mathrm{mL}^{-1}$ penicillin, $100 \mathrm{mg} \mathrm{mL}{ }^{-1}$ streptomycin) was added to Si-SPs or ${ }^{\mathrm{F}} \mathrm{Si}$-SPs at varying quantities. At defined time intervals, the cell media was aspirated (and stored at $-20{ }^{\circ} \mathrm{C}$ for future cell analysis) and replaced with fresh cell media.

Brain-derived U87MG glioblastoma cells were maintained in DMEM supplemented with $10 \%$ fetal bovine serum in a humidified incubator $\left(37^{\circ} \mathrm{C}, 5 \% \mathrm{CO}_{2}\right)$. U87MG cells were chosen as they are a human brain cell line, which is relevant for potential applications of the SPs in drug delivery to the human inner ear. U87MG cells were seeded in a 96-well plate at $2 \times 10^{4}$ cells per well in $100 \mu \mathrm{L}$ of medium and incubated overnight. Subsequently, $100 \mu \mathrm{L}$ of sample (degradation products from Si-SPs and ${ }^{\mathrm{F}} \mathrm{Si}$-SPs incubated in cell culture media and collected at different time points as described above) was added to each well and incubated $\left(37^{\circ} \mathrm{C}, 5 \%\right.$ 
$\mathrm{CO}_{2}$ ). After incubation for $48 \mathrm{~h}$, the cell culture medium was aspirated and $100 \mu \mathrm{L}$ of XTT/PMS solution was added to each well to measure cell viability. After incubation for $4 \mathrm{~h}$, the absorbance of the solution was measured using an Infinite M200 microplate reader at a wavelength of $475 \mathrm{~nm}$ and a reference wavelength of $675 \mathrm{~nm}$. Differential absorbance was calculated by subtracting absorbance at $675 \mathrm{~nm}$ from absorbance at $475 \mathrm{~nm}$. XTT/PMS solution was prepared by mixing $135 \mu \mathrm{L}$ of $2 \mathrm{mM}$ PMS in DPBS solution with $10.8 \mathrm{mg}$ XTT in $54 \mathrm{~mL}$ DMEM supplemented with $10 \%$ fetal bovine serum. Sample wells containing only medium (i.e., no cells) were used as background controls for the absorbance measurements. Cells exposed only to fresh DMEM were termed untreated controls and used for the normalization of cell toxicity.

\section{Minimum Information Reporting in Bio-Nano Experimental Literature (MIRIBEL).}

The studies conducted herein, including material characterization, biological characterization, and experimental details, conform to the MIRIBEL reporting standard for bio-nano research, ${ }^{41}$ and we include a companion checklist of these components in the Supporting Information.

\section{RESULTS AND DISCUSSION}

Synthesis of FSi-SPs. Si-SPs synthesized by gel-mediated electrospray assembly have been demonstrated to exhibit a high loading capacity and a sustained drug release for over 110 days. ${ }^{20}$ However, it was also noted that $\sim 60 \%$ of FITC-lysozyme pre-loaded in Si-SPs was released within the first 3 days. ${ }^{20}$ To delay this burst release, a biocoating strategy was developed herein to prepare ${ }^{\mathrm{F}} \mathrm{Si}-\mathrm{SPs}$ (fibrin-coated silica Si-SPs). As observed in Figure 1a-d, the Si-SPs and ${ }^{\mathrm{F}} \mathrm{Si}-\mathrm{SPs}$ were spherical and consisted of thousands of smaller porous silica particles. Incubation of Si-SPs with fibrinogen, followed by the enzyme thrombin, results in the enzymatic conversion of fibrinogen into a mesh of fibrin on the Si-SP surface. Fibrin is a fibrous non-globular protein that is involved in the process of blood clotting. ${ }^{34-36}$ SEM was used to examine the surface ultrastructure of SPs following fibrin coating. At low resolution, 
there is little observable difference in morphology between Si-SP and FSi-SP (Figure 1a, c), but at higher resolution, SEM imaging revealed distinct differences in the surface morphology of the SPs (Figure 1b, d) indicating the successful coating of the Si-SPs with fibrin, as evidenced by the film coverage of the intraparticle pores within the SPs. SEM-EDX elemental mapping confirmed the presence of silicon $(\mathrm{Si})$, oxygen $(\mathrm{O})$, calcium $(\mathrm{Ca})$, and nitrogen $(\mathrm{N})$ uniformly distributed on the surface of ${ }^{\mathrm{F}} \mathrm{Si}-\mathrm{SPs}$ (Figure 1e). FTIR spectroscopy of the Si-SPs confirmed the presence of $\mathrm{Si}-\mathrm{O}-\mathrm{Si}$ bonds with stretching vibrations of $\mathrm{Si}-\mathrm{O}-\mathrm{Si}$ observed at $1071 \mathrm{~cm}^{-1}$, bending vibrations of $\mathrm{O}-\mathrm{Si}-\mathrm{O}$ observed at $793 \mathrm{~cm}^{-1}$, and rocking vibrations of $\mathrm{Si}-$ O-Si observed at $455 \mathrm{~cm}^{-1}$ (Figure 1f, black curve). ${ }^{42}{ }^{\mathrm{F}} \mathrm{Si}-\mathrm{SPs}$ displayed a comparable FTIR spectrum (Figure 1f, red curve) except for the presence of an additional adsorption peak observed at $1645 \mathrm{~cm}^{-1}$, which may be assigned to the amine I band, due to the stretching vibration of $\mathrm{C}=\mathrm{O}$ and $\mathrm{C}-\mathrm{N}$ bands from fibrin in ${ }^{\mathrm{F}} \mathrm{Si}-\mathrm{SPs} .{ }^{43,44}$ The thickness and surface roughness of the fibrin coating were measured using AFM. Before the addition of thrombin, the fibrinogen coating had a thickness of $0.9 \pm 0.4 \mu \mathrm{m}$ with a root mean square roughness of $86 \pm 42 \mathrm{~nm}$. After exposure to thrombin and subsequent conversion to fibrin, the thickness increased to $2.3 \pm 0.3 \mu \mathrm{m}$ and the roughness also increased to $331 \pm 152 \mathrm{~nm}$ (Figure S6). Taken together, these results confirm the successful preparation of Si-SPs and the formation of a fibrin coating on the Si-SPs. 

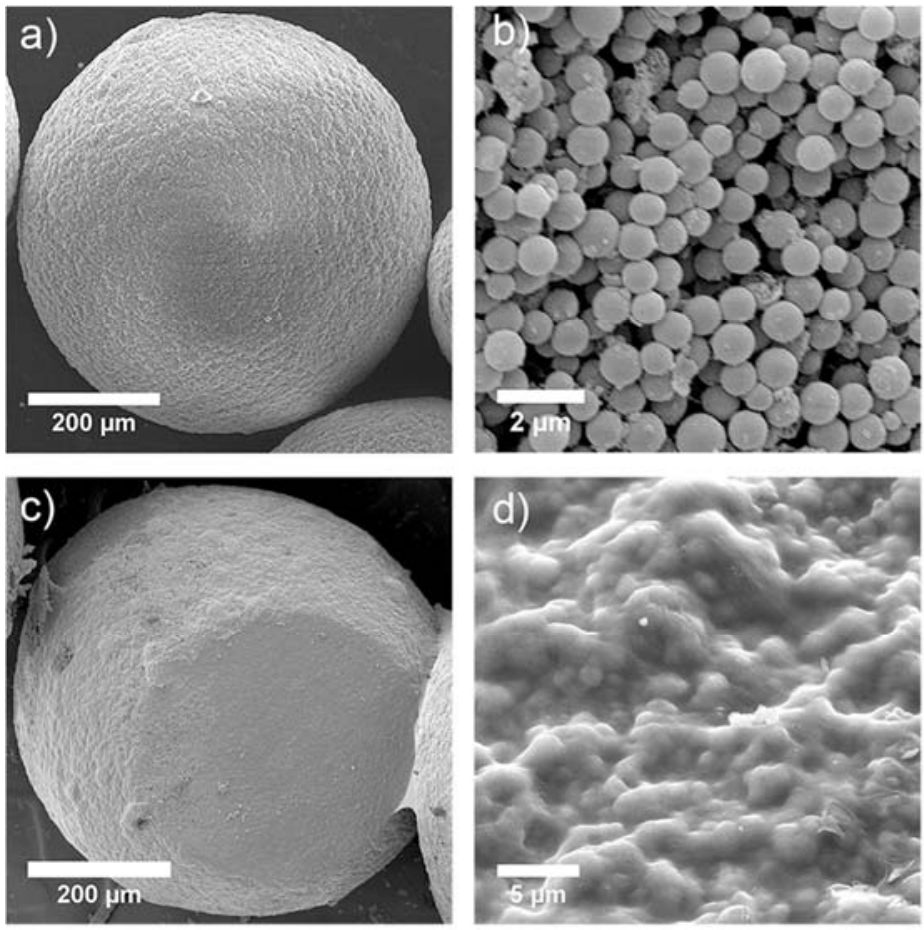

e)
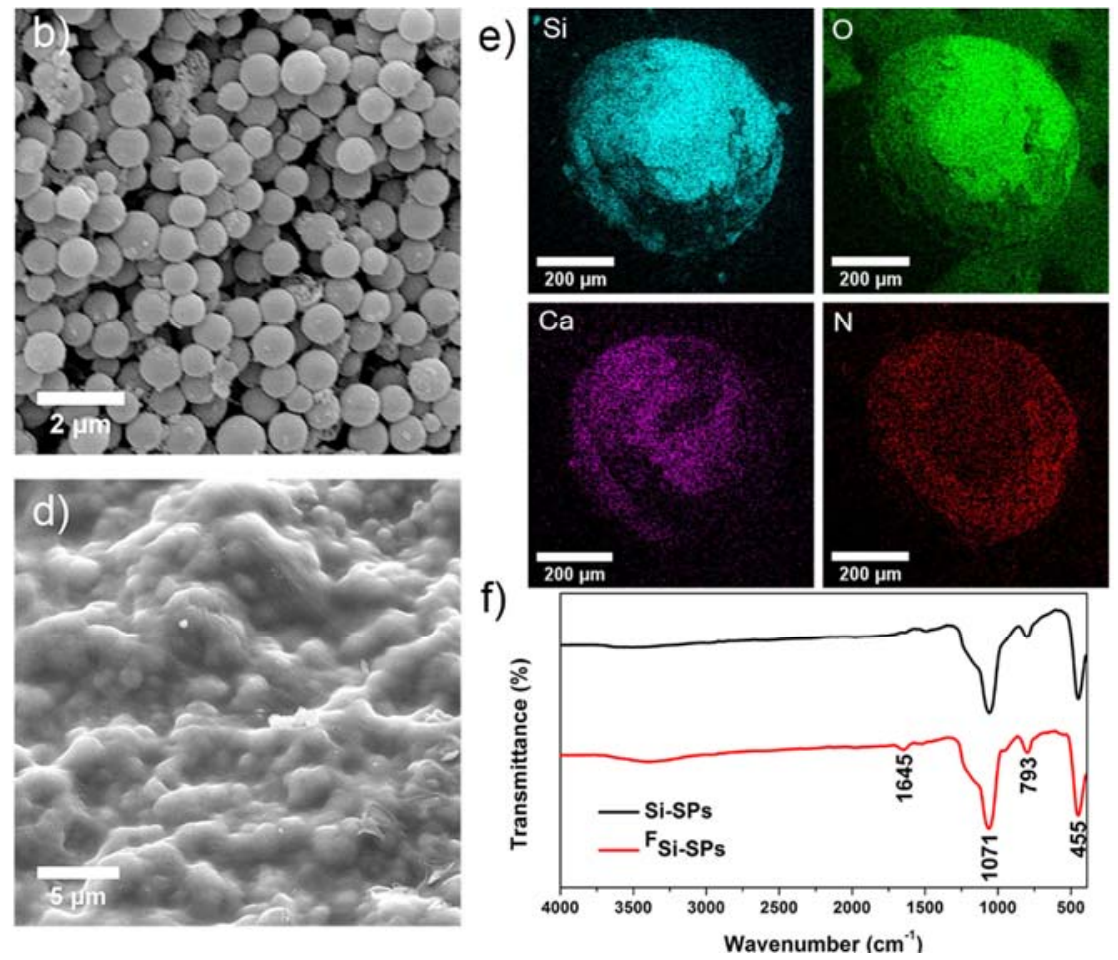

Figure 1. Characterization of Si-SPs and FSi-SPs. (a) SEM image of a Si-SP and (b) highresolution SEM image displaying the surface of a Si-SP. (c) SEM image of a Fi-SP and (d)

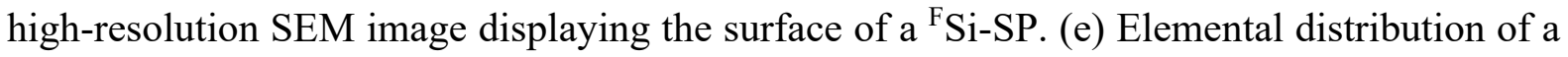

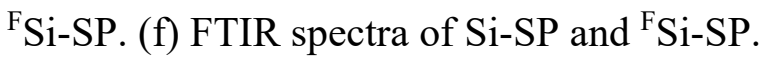

In Vitro Drug Release. Preloading a model protein therapeutic (FITC-lysozyme) into SiSPs (Scheme 1) followed by coating with a compact layer of fibrin as a "sealant" was hypothesized to slow the release of the entrapped drug from ${ }^{\mathrm{F}} \mathrm{Si}$-SPs. To evaluate FITClysozyme release profiles of ${ }^{\mathrm{F}} \mathrm{Si}$-SPs, FITC-lysozyme-loaded ${ }^{\mathrm{F}} \mathrm{Si}$-SPs were incubated in PBS $(\mathrm{pH} 7.4)$ at $37{ }^{\circ} \mathrm{C}$, and the supernatant was collected for protein content analysis at varying time points. A range of parameters for ${ }^{\mathrm{F}} \mathrm{Si}-\mathrm{SPs}$ synthesis were examined, including varying the concentration of fibrinogen (while keeping the concentration of thrombin constant) and the concentration of thrombin (while keeping the concentration of fibrinogen constant). FITClysozyme was loaded in Si-SPs (incubation for 3 days at $\sim 22^{\circ} \mathrm{C}$ ) to achieve an average loading amount of $7 \mu \mathrm{g}$ per SP. FITC-lysozyme loading in the Si-SPs prior to fibrin coating under different fibrinogen and thrombin concentrations are shown in Figure S7. The percentage of 
FITC-lysozyme released from the different SPs at each time point is shown in Figures S8 and S9, and the respective release profiles are shown in Figure 2a, b. Figure S10 shows the data fitted according to the first order release kinetics model. As noted in Figure 2a, b, both Si-SPs and ${ }^{\mathrm{F}} \mathrm{Si}-\mathrm{SPs}$ showed sustained FITC-lysozyme release profiles over 110 days. However, fibrin coating ( $\left.{ }^{\mathrm{F}} \mathrm{Si}-\mathrm{SPs}\right)$ resulted in a reduced initial release. Specifically, $>60 \%$ of protein was released from uncoated Si-SPs within 3 days. In comparison, release from ${ }^{2 \mathrm{~F} 1.72} \mathrm{Si}$-SPs (Si-SPs coated using $2 \mathrm{mg} \mathrm{mL}^{-1}$ fibrinogen and $1.72 \mathrm{mg} \mathrm{mL}^{-1}$ thrombin) occurred on a longer timescale of $>20$ days to achieve the same extent of release. The release period was further extended to 28 days when using ${ }^{20 \mathrm{~F} 1.72} \mathrm{Si}-\mathrm{SPs}$ and ${ }^{40 \mathrm{~F} 1.72} \mathrm{Si}-\mathrm{SPs}$ ( ${ }^{\mathrm{F}} \mathrm{Si}-\mathrm{SPs}$ prepared using higher concentrations of fibrinogen) (Figure 2a). Similarly, by applying different concentrations of thrombin, the release of FITC-lysozyme from ${ }^{\mathrm{F}} \mathrm{Si}-\mathrm{SPs}$ was slowed down although the actual thrombin concentration (from 0.1 to $5 \mathrm{mg} \mathrm{mL}^{-1}$ ) had little effect on the early release of the protein (in the first 12 days). This is reasonable as thrombin is an enzyme that converts soluble fibrinogen into insoluble ("sticky") fibrin, and the amount of thrombin (within a reasonable range) is not likely to limit the final quantity of fibrin fibers formed. As noted in Figure 2a, b, the cumulative drug release amount was lower than $100 \%$, likely due to the photobleaching of FITC that occurs over long periods of time and/or the presence of firmly adsorbed protein on the Si-SPs. ${ }^{45}$ Nevertheless, these results demonstrate that fibrin coating can substantially reduce the initial burst release of the model cargo FITC-lysozyme from Si-SPs.

This study was extended to clinically relevant neurotrophins, BDNF and NT-3, to assess the potential application of Si-SPs for inner ear neurotrophin delivery. BDNF or NT-3 was loaded in Si-SPs (incubation for 3 days at $\sim 22^{\circ} \mathrm{C}$ ), achieving an average loading of $7.3 \mu \mathrm{g}$ per SP. Fibrin coating of BDNF- and NT-3-loaded Si-SPs was performed using $20 \mathrm{mg} \mathrm{mL}^{-1}$ fibrinogen and $1.72 \mathrm{mg} \mathrm{mL}^{-1}$ thrombin. These parameters were chosen (and were used in all subsequent experiments), as they provided optimal delayed burst release based on the FITC-lysozyme 
studies discussed above. Figure $2 \mathrm{c}, \mathrm{d}$ shows the cumulative release profiles of BDNF and NT3 of Si-SPs and ${ }^{\mathrm{F}} \mathrm{Si}-\mathrm{SPs}$ in PBS (pH 7.4) at $37^{\circ} \mathrm{C}$. The release of both BDNF and NT-3 from ${ }^{\mathrm{F}} \mathrm{Si}$-SPs show decreased release rates compared with the release profile of uncoated Si-SPs, which is further demonstrated from the percentage of BDNF or NT-3 released from ${ }^{\mathrm{F}} \mathrm{Si}$-SPs at each time point (Figures S11 and S12). At day 21, $\sim 60 \%$ of the loaded BDNF or NT-3 was released from uncoated Si-SPs, whereas only $\sim 10 \%$ of the loaded BDNF or NT-3 was released from ${ }^{\mathrm{F}} \mathrm{Si}-\mathrm{SPs}$ (Figure 2c, d), indicating that the fibrin coating strategy can also delay the release of pre-loaded BDNF and NT-3. The lower release amount of BDNF/NT-3 from ${ }^{\text {FSi-SPs when }}$ compared with the release amount of FITC-lysosyme from ${ }^{\mathrm{F}} \mathrm{Si}$-SPs might be due to the stronger binding of BDNF/NT-3 to the fibrin matrix, resulting in extended BDNF and NT-3 retention

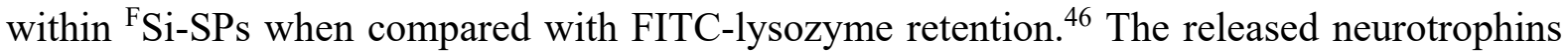
are expected to maintain their biological activity, as shown in our previous work after implantation of the SPs in the inner ear of guinea pigs. ${ }^{27,31}$

a)

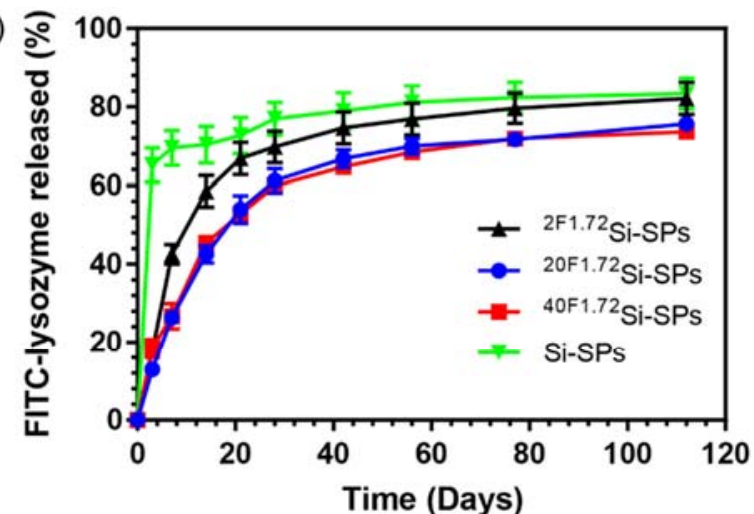

c)

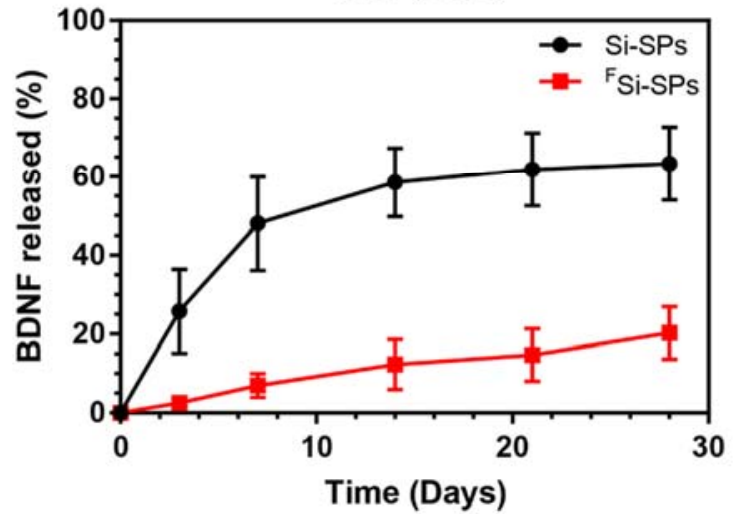

b)

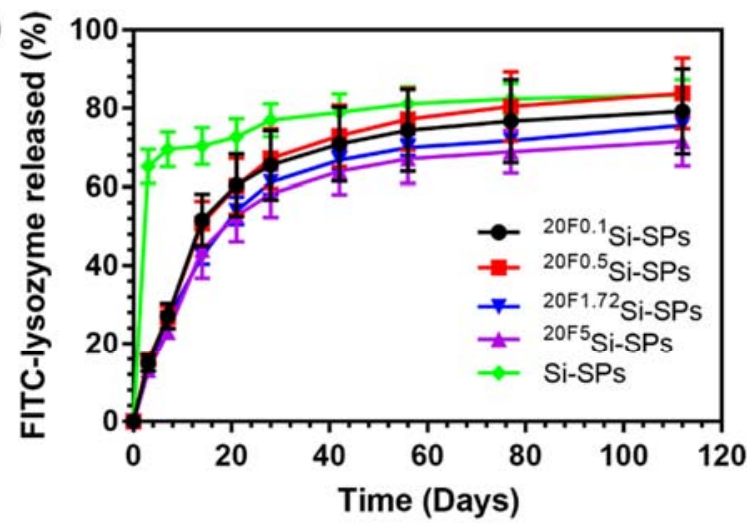

d)

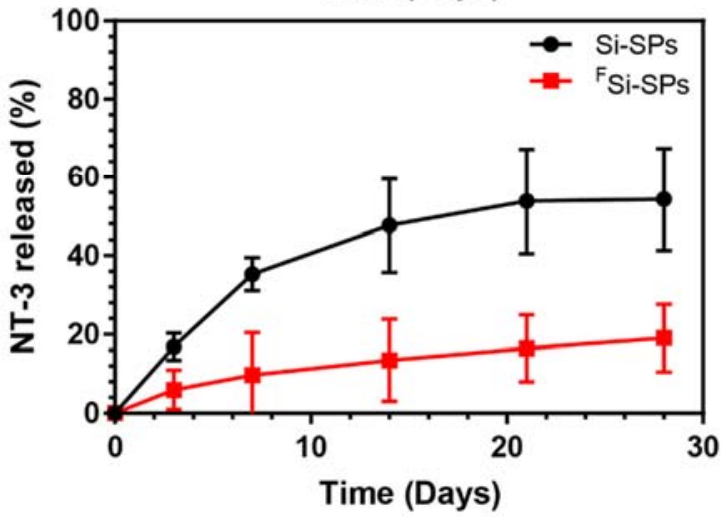


Figure 2. In vitro cumulative release profiles. (a) FITC-lysozyme release from Si-SPs and ${ }^{\mathrm{F}} \mathrm{Si}$ SPs (fibrin coating was obtained at varying concentrations of fibrinogen $(2,20$, and $40 \mathrm{mg}$ $\mathrm{mL}^{-1}$ ) while maintaining the concentration of thrombin at $1.72 \mathrm{mg} \mathrm{mL}^{-1}$; samples are respectively denoted as ${ }^{2 \mathrm{~F} 1.72} \mathrm{Si}-\mathrm{SPs},{ }^{20 \mathrm{~F} 1.72} \mathrm{Si}-\mathrm{SPs}$, and ${ }^{40 \mathrm{~F} 1.72} \mathrm{Si}-\mathrm{SPs}$ ). (b) FITC-lysozyme release from Si-SPs and ${ }^{\mathrm{F}} \mathrm{Si}-\mathrm{SPs}$ (fibrin coating was obtained at varying concentrations of thrombin $\left(0.1,0.5,1.72\right.$, and $\left.5 \mathrm{mg} \mathrm{mL}^{-1}\right)$, while keeping the concentration of fibrinogen constant at 20 $\mathrm{mg} \mathrm{mL}-1$; samples are respectively denoted as ${ }^{20 \mathrm{~F} 0.1} \mathrm{Si}-\mathrm{SPs},{ }^{20 \mathrm{~F} 0.5} \mathrm{Si}-\mathrm{SPs},{ }^{20 \mathrm{~F} 1.72} \mathrm{Si}-\mathrm{SPs}$, and ${ }^{20 \mathrm{~F} 5} \mathrm{Si}-$ SPs). Release profiles of (c) BDNF and (d) NT-3 from Si-SPs and ${ }^{\mathrm{F}} \mathrm{Si}$-SPs. Data presented in (a-d) are averages of triplicates with error bars indicating standard deviations, each measuring release from 10 SPs in $(a, b)$ and 1 SP in $(c, d)$. Release percentage data for individual time points are shown in Figures S8, S9, S11, S12.

Degradation of Si-SPs and ${ }^{\mathrm{F}} \mathrm{Si}-\mathrm{SPs}$. The release of lysozyme and BDNF/NT-3 from ${ }^{\mathrm{F}} \mathrm{Si}-$ SPs in PBS (in vitro) or the inner ear fluid (in vivo) is expected to occur partly as a result of concurrent dissolution of silica and degradation of the biodegradable fibrin coating. Silica has been generally recognized as safe by the U.S. Food and Drug Administration for over 50 years and is used as a food additive in various products. ${ }^{47}$ Silica-based nanomaterials can be degraded into nontoxic components (e.g., silicic acid or poly(silicic acid), which can be excreted through urine) and are of interest for diverse biomedical applications. ${ }^{47-49}$ Yamada et al. have demonstrated that the degradation of silica particles depends on the porosity and colloidal dispersity of the particles. ${ }^{48}$ In addition, the presence of calcium ions can accelerate the degradation of silica particles. ${ }^{42}$ In vitro degradation studies of the Si-SPs were performed by incubating Si-SPs or ${ }^{\mathrm{F}} \mathrm{Si}-\mathrm{SPs}$ in $\mathrm{PBS}\left(\mathrm{pH} \mathrm{7.4,} 37^{\circ} \mathrm{C}\right)$. SEM analysis revealed a progressive decrease in the size of the Si-SPs (Figure S13) and ${ }^{\mathrm{F}}$ Si-SPs (Figure 3a-e) over time and distinct degradation - the ${ }^{\mathrm{F}} \mathrm{Si}-\mathrm{SPs}$ had a cracked and collapsed morphology after incubation for 42 days (Figure 3d). After incubation for 70 days in PBS at $37{ }^{\circ} \mathrm{C}$, the diameter of ${ }^{\mathrm{F}} \mathrm{Si}$-SPs decreased 
by $\sim 40 \%$ and substantial changes in SP morphology were apparent when comparing ${ }^{\mathrm{F}} \mathrm{Si}$-SPs at day 3 (Figure 3a) and ${ }^{\mathrm{F}}$ Si-SPs at day 70 (Figure 3e). Higher magnification SEM imaging of the surface of ${ }^{\mathrm{F}} \mathrm{Si}$-SPs after incubation for 70 days (inset in Figure 3e) showed the appearance of the underlying primary silica particles, which also appeared fragmented, thus confirming the degradability of the fibrin coating. This was further confirmed by measuring the amount of fibrin remaining on the ${ }^{\mathrm{F}} \mathrm{Si}$-SPs (Figure S14) - a near-complete degradation of fibrin was evident after incubation for 42 days. At 28 days, which was the time needed to release $60 \%$ of the loaded FITC-lysozyme, only about 5\% of fibrin remained on the ${ }^{\mathrm{F} S i-S P s}$, after which the drug release profiles of Si-SPs and ${ }^{\mathrm{F}} \mathrm{Si}-\mathrm{SPs}$ became comparable (Figure 2a, b).

To quantify the release of Si from the SPs, ICP-OES was performed using samples collected at different time points $(3,7,14,21,28,42$, and 70 days) (Figure 3f). After incubation of the SPs for 70 days in PBS at $37{ }^{\circ} \mathrm{C}$, approximately $30 \%$ of Si was released from both the Si-SPs and ${ }^{\mathrm{F}} \mathrm{Si}-\mathrm{SPs}$. The extent of degradation of Si during the first 7 days appeared to be slightly lower for ${ }^{\mathrm{F}} \mathrm{Si}-\mathrm{SPs}$ than for Si-SPs, with $\sim 95 \%$ of silica remaining after 7 days for ${ }^{\mathrm{F}} \mathrm{Si}-\mathrm{SPs}$ compared to $\sim 90 \%$ for Si-SPs (Figure S15) — this indicates that the presence of the fibrin coating on the surface of ${ }^{\mathrm{F}} \mathrm{Si}$-SPs may impede on the degradation of the primary silica particles. After 14 days, ${ }^{\mathrm{F}} \mathrm{Si}$-SPs and Si-SPs displayed comparable degradation profiles (Figure $3 \mathrm{f}$ and Figure S15), as expected - only around less than $25 \%$ of fibrin remained on the ${ }^{\mathrm{F}} \mathrm{Si}$-SPs after 14 days (Figure S14) and most of the primary silica particles are therefore directly exposed in PBS (i.e., uncoated). 

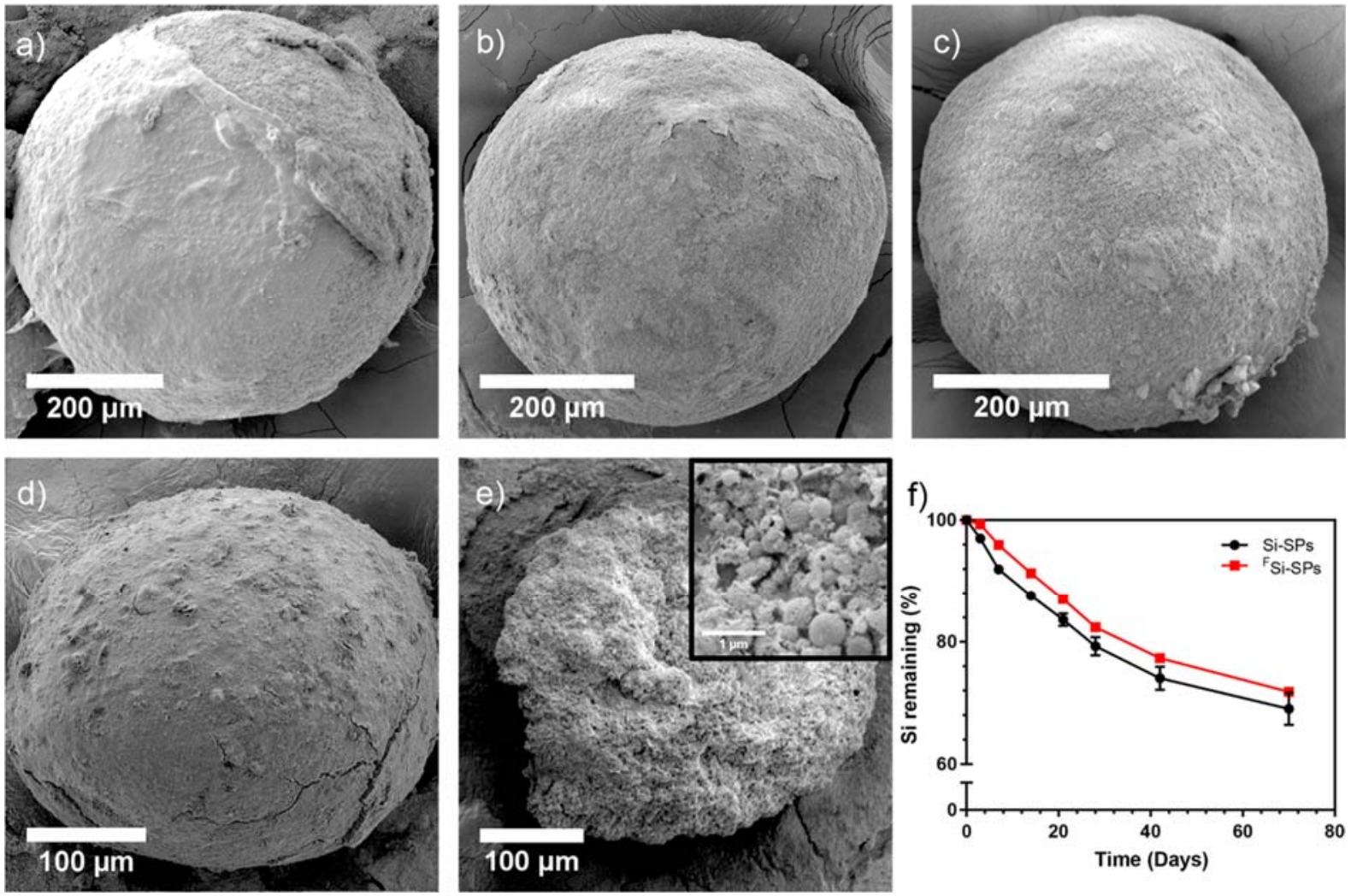

Figure 3. SEM images of ${ }^{\mathrm{F}} \mathrm{Si}-\mathrm{SPs}$ after incubation in PBS (pH 7.4) at $37{ }^{\circ} \mathrm{C}$ for (a) 3, (b) 14 , (c) 21, (d) 42, and (e) 70 days. Inset in (e) shows the surface structure of FSi-SPs after incubation for 70 days in PBS (pH 7.4) at $37{ }^{\circ} \mathrm{C}$. (Representative images of ${ }^{\mathrm{F}} \mathrm{Si}$-SPs before incubation are shown in Figure 1 and images of degraded Si-SPs are shown in Figure S13.) (f) ICP-OES analysis to quantify the Si released from Si-SPs and ${ }^{\mathrm{F}} \mathrm{Si}-\mathrm{SPs}$ throughout an incubation period of 70 days. ${ }^{\mathrm{F}} \mathrm{Si}-\mathrm{SPs}$ were prepared using $20 \mathrm{mg} \mathrm{mL}^{-1}$ of fibrinogen and $1.72 \mathrm{mg} \mathrm{mL}^{-1}$ of thrombin.

In Vitro Cytotoxicity. In our previous study, ${ }^{20}$ we showed, using an alamarBlue live/dead cell assay, that Si-SPs do not cause cytotoxicity to brain-derived U87MG glioblastoma cells after exposure to the cells for $48 \mathrm{~h}$. However, as Si-SPs and ${ }^{\mathrm{F}} \mathrm{Si}-\mathrm{SPs}$ are envisaged for use as drug depots for long-term, sustained drug release (>110 days), additional cytotoxicity experiments were undertaken herein to evaluate the release of any toxic components from SiSPs and ${ }^{\mathrm{F}} \mathrm{Si}$-SPs over longer timescales. The in vitro cytotoxicity of the degradation products 
of ${ }^{\mathrm{F}} \mathrm{Si}-\mathrm{SPs}$ was examined using U87MG cells. Supernatant containing fragmented Si and fibrin coating was collected over 77 days from $2,5,10$, or 15 FSi-SPs and added directly to cells, and the viability of the cells was measured after incubation for 2 days using XTT assay (Figure 4). No cytotoxicity arising from the degradation products of ${ }^{\mathrm{F}} \mathrm{Si}-\mathrm{SPs}$ was observed even as the number of ${ }^{\mathrm{F}} \mathrm{Si}$-SPs was increased from 2 to 15 . Similar results were observed for Si-SPs (Figure S16). These results support the biocompatibility of $\mathrm{Si}$ and fibrin and their corresponding breakdown products, and although the brain-derived U87MG cell line is a cancer cell line, the results are consistent with our previous study that demonstrated the biocompatibility of silicabased supraparticles in the cochlea of guinea pigs. ${ }^{31}$

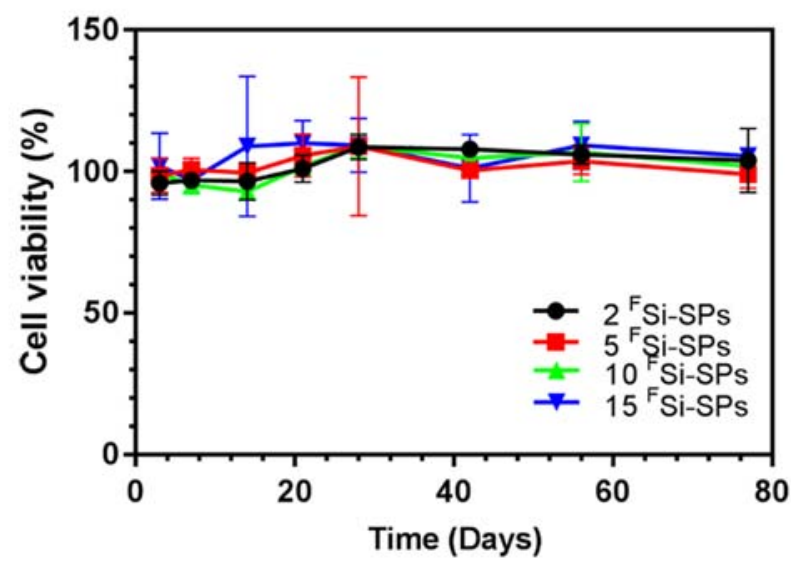

Figure 4. Cell viability of human brain glioblastoma cells after exposure for $48 \mathrm{~h}$ to cell media containing degradation products from $2,5,10$, or $15{ }^{\mathrm{F}} \mathrm{Si}$-SPs; the ${ }^{\mathrm{F}} \mathrm{Si}$-SPs were incubated in cell media for up to 77 days under sterile conditions. Each data point represents the average of triplicate wells with error bars indicating the standard deviation. Untreated cells (i.e., cells exposed to standard culture media only) were used to define $100 \%$ viability.

In Vitro Drug Release of FSi-SPs Encapsulated in an Alg-CaCO 3 Hydrogel. Hydrogel scaffolds, such as chitosan-glycerophosphate hydrogel, ${ }^{50}$ gelfoam, ${ }^{51}$ and peptide hydrogels, ${ }^{52}$ are commonly used as drug delivery systems for potential treatment of middle ear or inner ear diseases to aid in the local retention of drug within the ear and increase drug residence time, ${ }^{53}$ 
as well as to control pharmacokinetics in the ear. ${ }^{51,54}$ Fi-SPs embedded in a hydrogel scaffold may provide additional control of neurotrophin release, as well as aid in the surgical implantation and local retention of neurotrophin-loaded SPs in the target location. ${ }^{20}$ In the present study, a hydrogel system formed by cross-linking alginate and $\mathrm{Ca}^{2+}$ ions was investigated as an approach to achieve additional control of the release of protein therapeutics from Si-SPs. Alginate is a natural polysaccharide and has been shown to be biocompatible in the inner ear over long durations of implantation. ${ }^{55}$ In the present work, porous $\mathrm{CaCO}_{3}$ particles $\left(\sim 1.8 \mu \mathrm{m}\right.$ diameter) served as a source of $\mathrm{Ca}^{2+}$ to cross-link alginate into a hydrogel; crosslinking is initiated upon addition of GDL, a common food additive, which releases $\mathrm{Ca}^{2+}$ from $\mathrm{CaCO}_{3}$ particles. By administering drug-loaded Si-SPs in a liquid mixture containing alginate and $\mathrm{CaCO}_{3}$ particles, followed closely by the addition GDL to solidify the hydrogel into place, a triggered hydrogel-based controlled drug release platform can be realised. Owing to the high surface area of the porous $\mathrm{CaCO}_{3}$ particles and the mild hydrolysis conditions associated with GDL, gelation occurred within $\sim 2$ min following addition of GDL (Figure S17). SEM imaging revealed the porous structure of the resulting hydrogel material (Figure 5).

a)

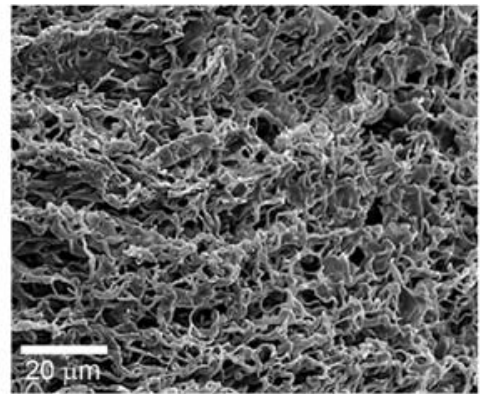

d)

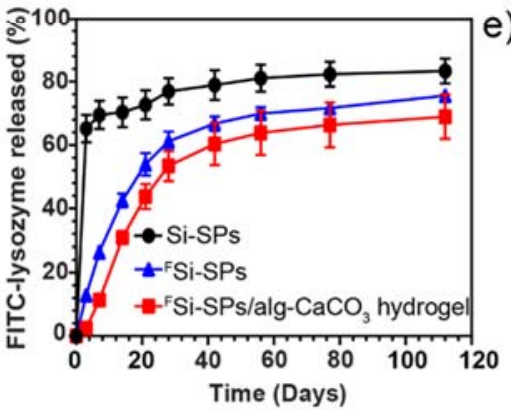

b)
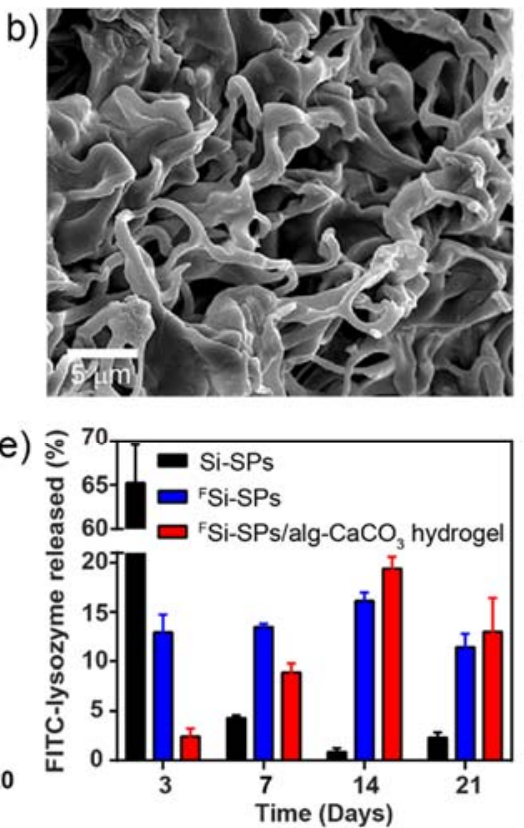

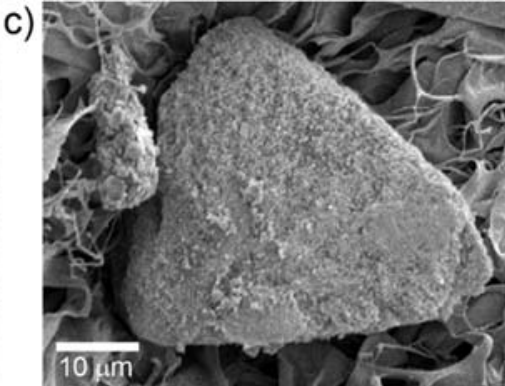

f)

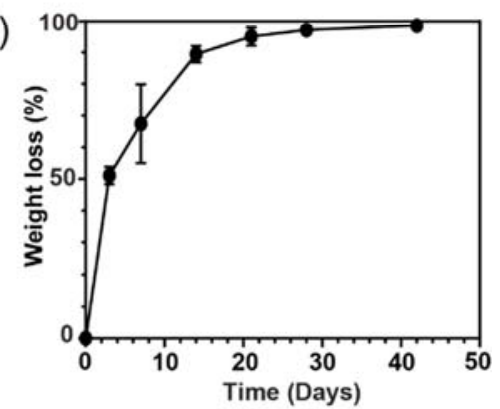


Figure 5. SEM images of the cross-section of lyophilized alg- $\mathrm{CaCO}_{3}$ hydrogel (synthesized using $2 \mathrm{wt} \%$ alginate solution and $1.5 \mathrm{mg}$ of $\mathrm{CaCO}_{3}$ particles) at (a) low and (b) high magnification. (c) SEM image of a fragment of ${ }^{\mathrm{F}} \mathrm{Si}-\mathrm{SPs}$ within the lyophilized alg- $\mathrm{CaCO}_{3}$ hydrogel. (d) In vitro cumulative FITC-lysozyme release profiles of Si-SPs, ${ }^{\mathrm{F}} \mathrm{Si}-\mathrm{SPs}$, and ${ }^{\mathrm{F}} \mathrm{Si}$ SPs/alg-CaCO 3 hydrogel. (e) Percentage of FITC-lysozyme released from Si-SPs, ${ }^{\mathrm{F}} \mathrm{Si}-\mathrm{SPs}$, and ${ }^{\mathrm{F}} \mathrm{Si}-\mathrm{SP}$ /alg- $\mathrm{CaCO}_{3}$ hydrogel in the first 21 days. (f) Degradation of alg- $\mathrm{CaCO}_{3}$ hydrogel in PBS (pH 7.4) at $37{ }^{\circ} \mathrm{C}$ monitored over 42 days. Data presented are averages of triplicates with error bars representing standard deviations.

FITC-lysozyme-loaded ${ }^{\mathrm{F}} \mathrm{Si}-\mathrm{SPs}$ were encapsulated within the alg-CaCO 3 hydrogel, and the release of FITC-lysozyme when incubated in PBS (pH 7.4) at $37^{\circ} \mathrm{C}$ was assessed (Figure 5d, e). The FITC-lysozyme loading values for the SP systems used in this study (Si-SPs, ${ }^{\text {F }} \mathrm{Si}-\mathrm{SPs}$, and ${ }^{\mathrm{F}} \mathrm{Si}-\mathrm{SPs}$ encapsulated in hydrogel or ${ }^{\mathrm{F}} \mathrm{Si}-\mathrm{SP} / \mathrm{alg}-\mathrm{CaCO}_{3}$ hydrogel) are shown in Figure S18. As demonstrated earlier, burst release can be delayed by applying a fibrin coating on the Si-SPs and Figure 5d shows that it can be delayed further in the presence of a hydrogel, with $\sim 60 \%$ of FITC-lysozyme released over 40 days. The difference in the amount of FITClysozyme released is more pronounced over the first 7 days — 25\%of FITC-lysozyme had been released from free ${ }^{\mathrm{F}} \mathrm{Si}-\mathrm{SPs}$ compared with $\sim 12 \%$ released from the ${ }^{\mathrm{F}} \mathrm{Si}$-SPs embedded in the hydrogel. After day 7, the release rates for samples with or without hydrogel (compare red and blue bars in Figure 5e) appear to be similar. This can be explained by the degradation of the hydrogel, which was $>80 \%$ degraded by day 14 (Figure 5f). Individual FITC-lysozyme release data (percentage release) for ${ }^{\mathrm{F}} \mathrm{Si}-\mathrm{SPs}$ and ${ }^{\mathrm{F}} \mathrm{Si}-\mathrm{SPs} /$ alg- $\mathrm{CaCO}_{3}$ hydrogel are shown in Figure S19. The observed reduction in release rate (Figure 5d) is in contrast to our previous report where the drug release rate was accelerated by using a poloxamer-based hydrogel system. ${ }^{20}$ These results demonstrate that different hydrogel systems can be used to either accelerate or delay protein release from loaded Si-SPs. Furthermore, the in vitro release profiles 
of Si-SPs/alg- $\mathrm{CaCO}_{3}$ hydrogels were investigated using varying amounts of $\mathrm{CaCO}_{3}$ particles and concentrations of alginate solution (Figure S20). The protein loading values are shown in Figure S21. No large differences in the FITC-lysozyme release profile from the different SiSP platforms examined were observed (Figure S20). Taken together, these results show that an alg- $\mathrm{CaCO}_{3}$ hydrogel system, wherein gelation is triggered by the addition of GDL, can encapsulate drug-loaded Si-SPs with robust release profiles. The intended use is as a simple two-component, "mix-and-inject" system where a clinician or surgeon can place the drug delivery system at the intended location, such as in the middle ear or inner ear.

\section{CONCLUSIONS}

We demonstrated the engineering of fibrin-coated Si-SPs (FSi-SPs) with a high loading capacity $(\sim 7 \mu \mathrm{g}$ per SP; $\sim 140 \mu \mathrm{g}$ mg-1) that can act as a long-term drug delivery system with biocompatibility and degradability and improved drug release performance. A bio-inspired coating approach involving the endogenous protein fibrin (enzymatically converted from fibrinogen) was used to considerably reduce the initial rapid release (i.e., burst release) observed for uncoated Si-SPs to overcome the problem of rapid initial loss of drug from the reservoir and potential side effects associated with high initial dosing. The uncoated Si-SPs released $>60 \%$ of cargo protein in the first 3 days, whereas release from FSi-SPs occurred over a longer period of $>20$ days, representing a $>6$-fold improvement. The fibrin coating is biodegradable ( $<25 \%$ of coating remained after 20 days) and sustained release of the encapsulated protein from the FSi-SPs was observed over 110 days. The release behavior of Si-SPs could be modified further by encapsulating the drug-loaded FSi-SPs into an alg-CaCO3 hydrogel — encapsulation into a hydrogen resulted in reduced initial release of the loaded protein, while also enabling future clinical use by facilitating SP localization and retention. Interestingly, the alg-CaCO3 hydrogel system presented here has an opposite effect on the SP release rate (i.e., retards instead of accelerates) when compared with our previous report using 
poloxamer-based hydrogels. ${ }^{20}$ Our results provide further evidence of the versatility of SP drug delivery systems and present strategies (biocoatings and hydrogel platforms, of which the gelation can be triggered by external stimuli) to tailor the drug release profiles of Si-SPs to facilitate their future clinical application in long-term, protein drug delivery.

\section{ASSOCIATED CONTENT}

Supporting Information. SEM images of $\mathrm{CaCO}_{3}$ particles; calibration curves for FITClysozyme, BDNF, and NT-3 concentration determination; calibration curves for silicon concentration determination; FITC-lysozyme, BDNF, and NT-3 release percentage data from Si-SPs or ${ }^{\mathrm{F}} \mathrm{Si}-\mathrm{SPs}$ at individual time points; FITC-lysozyme release percentage data from ${ }^{\mathrm{F}} \mathrm{Si}-$ SPs/alg- $\mathrm{CaCO}_{3}$ hydrogel at individual time points; FITC-lysozyme loading amount in Si-SPs before coating with different concentrations of fibrinogen or thrombin; in vitro fibrin degradation curve; SEM images of the degradation of Si-SPs; in vitro Si degradation of Si-SPs and ${ }^{\mathrm{F}} \mathrm{Si}-\mathrm{SPs}$; cell viability of Si-SPs over 77 days; photographs of the formation of alg-CaCO 3 hydrogel; FITC-lysozyme loading amounts in different SPs; in vitro FITC-lysozyme release profiles of Si-SPs and ${ }^{\mathrm{F}} \mathrm{Si}-\mathrm{SPs}$ prepared by incorporation in alg-CaCO 3 hydrogel at varying concentrations of alginate or amounts of $\mathrm{CaCO}_{3}$ particles; MIRIBEL checklist including material characterization, biological characterization and experimental details.

\section{AUTHOR INFORMATION}

\section{Corresponding author}

*E-mail: awise@bionicsinstitute.org

*E-mail: fcaruso@unimelb.edu.au

\section{Notes}

The authors declare no competing financial interests. 


\section{ACKNOWLEDGMENTS}

This research was conducted and funded by the Australian Research Council Centre of Excellence in Convergent Bio-Nano Science and Technology (project number CE140100036), the Australian National Health and Medical Research Council (NHMRC) Project Grants GNT1064375 and GNT1142910, the US Department of Defense (W81XWH1810276), and the Robert Bulley Foundation. F.C. acknowledges the award of an NHMRC Senior Principal Research Fellowship (GNT1135806). The Bionics Institute acknowledges the support it receives from the Victorian Government through its Operational Infrastructure Support Program. M.B. acknowledges support from Horizon 2020 (European Union) through a Marie Skłodowska-Curie Individual Fellowship (grant agreement no. 745676). We also thank Dr. Yi Ju and Yijiao Qu for helpful discussions

\section{REFERENCES}

(1) Bahrami, B.; Hojjat-Farsangi, M.; Mohammadi, H.; Anvari, E.; Ghalamfarsa, G.; Yousefi, M.; Jadidi-Niaragh, F. Nanoparticles and Targeted Drug Delivery in Cancer Therapy. Immunol. Lett. 2017, 190, 64-83.

(2) Björnmalm, M.; Thurecht, K. J.; Michael, M.; Scott, A. M.; Caruso, F. Bridging Bio-Nano Science and Cancer Nanomedicine. ACS Nano 2017, 11, 9594-9613.

(3) Mamo, T.; Moseman, E. A.; Kolishetti, N.; Salvador-Morales, C.; Shi, J.; Kuritzkes, D. R.; Langer, R.; von Andrian, U.; Farokhzad, O. C. Emerging Nanotechnology Approaches for HIV/AIDS Treatment and Prevention. Nanomedicine 2010, 5, 269-285.

(4) Barcia, E.; Boeva, L.; García-García, L.; Slowing, K.; Fernández-Carballido, A.; Casanova, Y.; Negro, S. Nanotechnology-Based Drug Delivery of Ropinirole for Parkinson's Disease. Drug Delivery 2017, 24, 1112-1123. 
(5) Furtado, D.; Björnmalm, M.; Ayton, S.; Bush, A. I.; Kempe, K.; Caruso, F. Overcoming the Blood-Brain Barrier: The Role of Nanomaterials in Treating Neurological Diseases. $A d v$. Mater. 2018, 30, 1801362.

(6) Kauscher, U.; Holme, M. N.; Björnmalm, M.; Stevens, M. M. Physical Stimuli-Responsive Vesicles in Drug Delivery: Beyond Liposomes and Polymersomes. Adv. Drug Delivery Rev. 2019, 138, 259-275.

(7) Cui, J.; Björnmalm, M.; Ju, Y.; Caruso, F. Nanoengineering of Poly(ethylene glycol) Particles for Stealth and Targeting. Langmuir 2018, 34, 10817-10827.

(8) Zhou, Y.; Quan, G.; Wu, Q.; Zhang, X.; Niu, B.; Wu, B.; Huang, Y.; Pan, X.; Wu, C. Mesoporous Silica Nanoparticles for Drug and Gene Delivery. Acta Pharm. Sin. B 2018, 8, $165-177$.

(9) Dai, Q.; Bertleff-Zieschang, N.; Braunger, J. A.; Björnmalm, M.; Cortez-Jugo, C.; Caruso, F. Particle Targeting in Complex Biological Media. Adv. Healthcare Mater. 2018, 7, 1700575.

(10) Huang, X.; Brazel, C. S. On the Importance and Mechanisms of Burst Release in MatrixControlled Drug Delivery Systems. J. Controlled Release 2001, 73, 121-136.

(11) Lee, J. H.; Yeo, Y. Controlled Drug Release from Pharmaceutical Nanocarriers. Chem. Eng. Sci. 2015, 125, 75-84.

(12) Fonseca, C.; Simoes, S.; Gaspar, R. Paclitaxel-Loaded PLGA Nanoparticles: Preparation, Physicochemical Characterization and In Vitro Anti-Tumoral Activity. J. Controlled Release 2002, 83, 273-286.

(13) Kim, J.; Lee, J. E.; Lee, J.; Yu, J. H.; Kim, B. C.; An, K.; Hwang, Y.; Shin, C.-H.; Park, J.-G.; Kim, J. Magnetic Fluorescent Delivery Vehicle Using Uniform Mesoporous Silica 
Spheres Embedded with Monodisperse Magnetic and Semiconductor Nanocrystals. J. Am. Chem. Soc. 2006, 128, 688-689.

(14) Pakulska, M. M.; Elliott Donaghue, I.; Obermeyer, J. M.; Tuladhar, A.; McLaughlin, C. K.; Shendruk, T. N.; Shoichet, M. S. Encapsulation-Free Controlled Release: Electrostatic Adsorption Eliminates the Need for Protein Encapsulation in PLGA Nanoparticles. Sci. Adv. 2016, 2, e1600519.

(15) Maggini, L.; Cabrera, I.; Ruiz-Carretero, A.; Prasetyanto, E. A.; Robinet, E.; De Cola, L. Breakable Mesoporous Silica Nanoparticles for Targeted Drug Delivery. Nanoscale 2016, 8, $7240-7247$.

(16) Zhang, Q.; Shen, C.; Zhao, N.; Xu, F. J. Redox-Responsive and Drug-Embedded Silica Nanoparticles with Unique Self-Destruction Features for Efficient Gene/Drug Codelivery. $A d v$. Funct. Mater. 2017, 27, 1606229.

(17) Yoo, H. S.; Park, T. G. Biodegradable Polymeric Micelles Composed of Doxorubicin Conjugated PLGA-PEG Block Copolymer. J. Controlled Release 2001, 70, 63-70.

(18) Rim, H. P.; Min, K. H.; Lee, H. J.; Jeong, S. Y.; Lee, S. C. pH-Tunable Calcium Phosphate Covered Mesoporous Silica Nanocontainers for Intracellular Controlled Release of Guest Drugs. Angew. Chem. Int. Ed. 2011, 50, 8853-8857.

(19) Maiolo, D.; Pigliacelli, C.; Sanchez Moreno, P.; Violatto, M. B.; Talamini, L.; Tirotta, I.; Piccirillo, R.; Zucchetti, M.; Morosi, L.; Frapolli, R.; Candiani, G.; Bigini, P.; Metrangolo, P.; Baldelli Bombelli, F. Bioreducible Hydrophobin-Stabilized Supraparticles for Selective Intracellular Release. ACS Nano 2017, 11, 9413-9423. 
(20) Ma, Y.; Björnmalm, M.; Wise, A. K.; Cortez-Jugo, C.; Revalor, E.; Ju, Y.; Feeney, O. M.; Richardson, R. T.; Hanssen, E.; Shepherd, R. K.; Porter, C. J. H.; Caruso, F. Gel-Mediated Electrospray Assembly of Silica Supraparticles for Sustained Drug Delivery. ACS Appl. Mater. Interfaces 2018, 10, 31019-31031.

(21) Wan, G.; Gomez-Casati, M. E.; Gigliello, A. R.; Liberman, M. C.; Corfas, G. Neurotrophin-3 Regulates Ribbon Synapse Density in the Cochlea and Induces Synapse Regeneration after Acoustic Trauma. Elife 2014, 3, e03564.

(22) Farinas, I.; Jones, K. R.; Tessarollo, L.; Vigers, A. J.; Huang, E.; Kirstein, M.; de Caprona, D. C.; Coppola, V.; Backus, C.; Reichardt, L. F.; Fritzsch, B. Spatial Shaping of Cochlear Innervation by Temporally Regulated Neurotrophin Expression. J. Neurosci. 2001, 21, 61706180.

(23) Huang, E. J.; Reichardt, L. F. Neurotrophins: Roles in Neuronal Development and Function. Annu. Rev. Neurosci. 2001, 24, 677-736.

(24) Bibel, M.; Barde, Y. A. Neurotrophins: Key Regulators of Cell Fate and Cell Shape in the Vertebrate Nervous System. Genes Dev. 2000, 14, 2919-2937.

(25) Lu, Z. D.; Yin, Y. D. Colloidal Nanoparticle Clusters: Functional Materials by Design. Chem. Soc. Rev. 2012, 41, 6874-6887.

(26) Sperling, M.; Gradzielski, M. Droplets, Evaporation and a Superhydrophobic Surface: Simple Tools for Guiding Colloidal Particles into Complex Materials. Gels 2017, 3, 15.

(27) Wang, Y.; Wise, A. K.; Tan, J.; Maina, J. W.; Shepherd, R. K.; Caruso, F. Mesoporous Silica Supraparticles for Sustained Inner-Ear Drug Delivery. Small 2014, 10, 4244-4248. 
(28) Maina, J.; Cui, J.; Björnmalm, M.; Wise, A. K.; Shepherd, R. K.; Caruso, F. MoldTemplated Inorganic-Organic Hybrid Supraparticles for Codelivery of Drugs. Biomacromolecules 2014, 15, 4146-4151.

(29) Björnmalm, M.; Cui, J.; Bertleff-Zieschang, N.; Song, D.; Faria, M.; Rahim, M. A.; Caruso, F. Nanoengineering Particles through Template Assembly. Chem. Mater. 2017, 29, 289-306.

(30) Schmidt, N.; Schulze, J.; Warwas, D. P.; Ehlert, N.; Lenarz, T.; Warnecke, A.; Behrens, P. Long-Term Delivery of Brain-Derived Neurotrophic Factor (BDNF) from Nanoporous Silica Nanoparticles Improves the Survival of Spiral Ganglion Neurons In Vitro. PLoS One 2018, 13, e0194778.

(31) Wise, A. K.; Tan, J.; Wang, Y.; Caruso, F.; Shepherd, R. K. Improved Auditory Nerve Survival with Nanoengineered Supraparticles for Neurotrophin Delivery into the Deafened Cochlea. PLoS One 2016, 11, e0164867.

(32) Scharfman, H. E.; Goodman, J. H.; Sollas, A. L.; Croll, S. D. Spontaneous Limbic Seizures after Intrahippocampal Infusion of Brain-Derived Neurotrophic Factor. Exp. Neurol. 2002, 174, 201-214.

(33) Binder, D. K.; Croll, S. D.; Gall, C. M.; Scharfman, H. E. BDNF and Epilepsy: Too Much of a Good Thing? Trends Neurosci. 2001, 24, 47-53.

(34) Wolberg, A. S.; Campbell, R. A. Thrombin Generation, Fibrin Clot Formation and Hemostasis. Transfus. Apheresis Sci. 2008, 38, 15-23.

(35) Kattula, S.; Byrnes, J. R.; Wolberg, A. S. Fibrinogen and Fibrin in Hemostasis and Thrombosis. Arterioscler., Thromb., Vasc. Biol. 2017, 37, e13. 
(36) Weisel, J. W.; Litvinov, R. I. Fibrin Formation, Structure and Properties. In Fibrous Proteins: Structures and Mechanisms. Subcellular Biochemistry; Parry, D., Squire J., Eds.; Springer Internation Publishing, 2017; Vol. 82, pp. 405-456.

(37) Li, J.; Linderman, S. W.; Zhu, C.; Liu, H.; Thomopoulos, S.; Xia, Y. Surgical Sutures with Porous Sheaths for the Sustained Release of Growth Factors. Adv. Mater. 2016, 28, 4620-4624.

(38) Cui, J.; De Rose, R.; Alt, K.; Alcantara, S.; Paterson, B. M.; Liang, K.; Hu, M.; Richardson, J. J.; Yan, Y.; Jeffery, C. M.; Price, R. I.; Peter, K.; Hagemeyer, C. E.; Donnelly, P. S.; Kent, S. J.; Caruso, F. Engineering Poly(ethylene glycol) Particles for Improved Biodistribution. ACS Nano 2015, 9, 1571-1580.

(39) Wang, Y.; Moo, Y. X.; Chen, C.; Gunawan, P.; Xu, R. Fast Precipitation of Uniform $\mathrm{CaCO}_{3}$ Nanospheres and Their Transformation to Hollow Hydroxyapatite Nanospheres. $J$. Colloid Interface Sci. 2010, 352, 393-400.

(40) Wang, C.; Liu, H.; Gao, Q.; Liu, X.; Tong, Z. Alginate-Calcium Carbonate Porous Microparticle Hybrid Hydrogels with Versatile Drug Loading Capabilities and Variable Mechanical Strengths. Carbohydr. Polym. 2008, 71, 476-480.

(41) Faria, M.; Björnmalm, M.; Thurecht, K. J.; Kent, S. J.; Parton, R. G.; Kavallaris, M.; Johnston, A. P. R.; Gooding, J. J.; Corrie, S. R.; Boyd, B. J.; Thordarson, P.; Whittaker, A. K.; Stevens, M. M.; Prestidge, C. A.; Porter, C. J. H.; Parak, W. J.; Davis, T. P.; Crampin, E. J.; Caruso, F. Minimum Information Reporting in Bio-Nano Experimental Literature. Nat. Nanotechnol. 2018, 13, 777-785.

(42) Hao, X.; Hu, X.; Zhang, C.; Chen, S.; Li, Z.; Yang, X.; Liu, H.; Jia, G.; Liu, D.; Ge, K.; Liang, X. J.; Zhang, J. Hybrid Mesoporous Silica-Based Drug Carrier Nanostructures with Improved Degradability by Hydroxyapatite. ACS Nano 2015, 9, 9614-9625. 
(43) Litvinov, R. I.; Faizullin, D. A.; Zuev, Y. F.; Weisel, J. W. The $\alpha$-Helix to $\beta$-Sheet Transition in Stretched and Compressed Hydrated Fibrin Clots. Biophys. J. 2012, 103, 10201027.

(44) Bramanti, E.; Benedetti, E.; Sagripanti, A.; Papineschi, F.; Benedetti, E. Determination of Secondary Structure of Normal Fibrin from Human Peripheral Blood. Biopolymers 1997, 41, $545-553$.

(45) Deka, C.; Lehnert, B. E.; Lehnert, N. M.; Jones, G. M.; Sklar, L. A.; Steinkamp, J. A. Analysis of Fluorescence Lifetime and Quenching of FITC-Conjugated Antibodies on Cells by Phase-Sensitive Flow Cytometry. Cytometry 1996, 25, 271-279.

(46) Martino, M. M.; Briquez, P. S.; Ranga, A.; Lutolf, M. P.; Hubbell, J. A. Heparin-Binding Domain of Fibrin(ogen) Binds Growth Factors and Promotes Tissue Repair When Incorporated within a Synthetic Matrix. Proc. Natl. Acad. Sci. U.S.A. 2013, 110, 4563-4568.

(47) Croissant, J. G.; Fatieiev, Y.; Khashab, N. M. Degradability and Clearance of Silicon, Organosilica, Silsesquioxane, Silica Mixed Oxide, and Mesoporous Silica Nanoparticles. Adv. Mater. 2017, 29, 1604634.

(48) Yamada, H.; Urata, C.; Ujiie, H.; Yamauchi, Y.; Kuroda, K. Preparation of Aqueous Colloidal Mesostructured and Mesoporous Silica Nanoparticles with Controlled Particle Size in a Very Wide Range from $20 \mathrm{~nm}$ to $700 \mathrm{~nm}$. Nanoscale 2012, 5, 6145-6153.

(49) Dietzel, M. Dissolution of Silicates and the Stability of Polysilicic Acid. Geochim. Cosmochim. Acta 2000, 64, 3275-3281.

(50) Paulson, D. P.; Abuzeid, W.; Jiang, H.; Oe, T.; O’Malley, B. W.; Li, D. A Novel Controlled Local Drug Delivery System for Inner Ear Disease. Laryngoscope 2008, 118, 706711. 
(51) Havenith, S.; Versnel, H.; Agterberg, M. J.; de Groot, J. C.; Sedee, R. J.; Grolman, W.; Klis, S. F. Spiral Ganglion Cell Survival after Round Window Membrane Application of BrainDerived Neurotrophic Factor Using Gelfoam as Carrier. Hear. Res. 2011, 272, 168-177.

(52) Koutsopoulos, S.; Unsworth, L. D.; Nagai, Y.; Zhang, S. Controlled Release of Functional Proteins through Designer Self-Assembling Peptide Nanofiber Hydrogel Scaffold. Proc. Natl. Acad. Sci. U.S.A. 2009, 106, 4623-4628.

(53) Liu, H.; Zhou, Y.; Chen, S.; Bu, M.; Xin, J.; Li, S. Current Sustained Delivery Strategies for the Design of Local Neurotrophic Factors in Treatment of Neurological Disorders. Asian J. Pharm. Sci. 2013, 8, 269-277.

(54) Yang, R.; Sabharwal, V.; Okonkwo, O. S.; Shlykova, N.; Tong, R.; Lin, L. Y.; Wang, W.; Guo, S.; Rosowski, J. J.; Pelton, S. I.; Kohane, D. S. Treatment of Otitis Media by Transtympanic Delivery of Antibiotics. Sci. Transl. Med. 2016, 8, 356ra120.

(55) Wise, A. K.; Fallon, J. B.; Neil, A. J.; Pettingill, L. N.; Geaney, M. S.; Skinner, S. J.; Shepherd, R. K. Combining Cell-Based Therapies and Neural Prostheses to Promote Neural Survival. Neurotherapeutics 2011, 8, 774-787. 
For Table of Contents Use Only

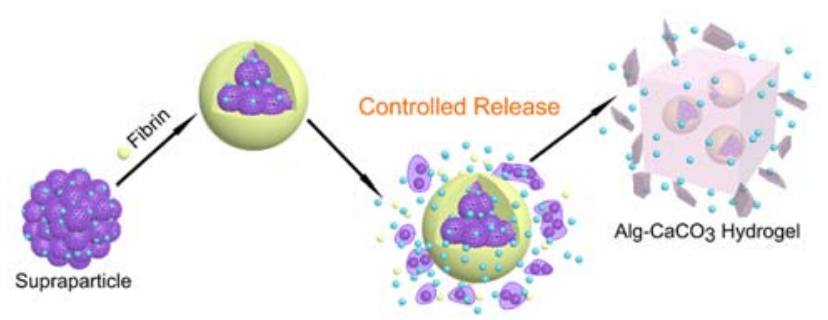

